\title{
Application of AHP/EVAMIX Method for Decision Making in the Industrial Environment
}

\author{
Veera P. Darji, Ravipudi V. Rao \\ Department of Mechanical Engineering, S.V. National Institute of Technology, Surat, India \\ Email: veera.jani@rediffmail.com, ravipudirao@gmail.com
}

Received October 1, 2013; revised November 1, 2013; accepted November 8, 2013

Copyright (C) 2013 Veera P. Darji, Ravipudi V. Rao. This is an open access article distributed under the Creative Commons Attribution License, which permits unrestricted use, distribution, and reproduction in any medium, provided the original work is properly cited.

\begin{abstract}
Selection of best alternative among multiple alternatives is a tough task for decision makers in many industrial situations. This paper explores the applicability and capability of an outranking method known as Evaluation of Mixed Data (EVAMIX) method combined with Analytical Hierarchy Process (AHP) for selection of right alternative. The novelty of the proposed methodology is its capability of dealing with both ordinal and cardinal information. The integrated approach is a significant tool of the decision making process in industrial environments. Five examples are illustrated to show the effectiveness of method.
\end{abstract}

Keywords: Industrial Environment; Decision Making; AHP; EVAMIX

\section{Introduction}

In a competitive industrial environment customers as well as manufacturers are becoming more conscious and inclined to demand a particular number of customised products at a particular speed. Therefore it becomes important for the manufacturers to keep pace with dynamic conditions and rapid changes, be innovative, and adapt to new systems, techniques and methodologies. Because of all these factors, the industries and manufacturers have begun to make radical changes in their system and structures through cost reduction, by achieving higher economic benefit plus environmental benefit to maintain their position in the global market. The measurement of the efficiency level of a manufacturing system is a very critical challenge. Material selection, site selection, Flexible Manufacturing System selection, Robot selection, computer-integrated manufacturing system selection, AGV selection, facility layout selection, robot selection, process selection, machine tool selection, cutting fluid selection etc. are some of the major issues of industrial environment.

The advancements in the manufacturing technologies have brought about a metamorphism in the world Industrial scene. The advancements include CNC, CAD/CAM, FMS, robotics, rapid prototyping, environmentally sustainable technologies, etc., which have become an integral part of manufacturing. What are parallel to this are the rapid strides in the development of new products and the emergence of an open economy leading to global competition. Manufacturing industries are compelled to move away from traditional set-ups to more responsive and dynamic ones. There is a need for simple, systematic, and logical methods or mathematical tools to guide decision makers in considering a number of selection attributes and their interrelations. The objective of any selection procedure is to identify appropriate selection attributes, and obtain the most appropriate combination of attributes in conjunction with the real requirements. Thus, effort needs to be extended to identify those attributes that influence an alternative selection for a given problem, using simple and logical methods to eliminate unsuitable alternatives and to select the most appropriate alternatives to strengthen the existing selection procedures. The selection of right alternative makes a significant change in the productivity and profitability of the manufacturing industries [1].

In order to evaluate the overall effectiveness of the candidate alternatives and to select the best option, the multicriteria decision making method requires decomposing the problem into step such as: defining a set of attributes which mostly influence the alternative, preparing a decision matrix, weighing the criteria based on past experience or using an appropriate method, evaluating the alternatives and ranking them from best to worst. 
Thus, it is required to extend the decision making method in simple, effective and logical way. This paper presents a very useful outranking method known as Evaluation of Mixed Data (EVAMIX) combined with Analytical Hierarchy Process (AHP).

The literature shows some applications in the field of multi criteria analysis in material selection by Chatterjee et al. [2], environmental planning by Voogd [3,4], stateof-art survey for MCDA proposed by Martel and Matarazoo [5], multi criteria analysis in physical planning discussed in Nijkamp et al. [6], comparison of various alternatives in water resource management carried by Hajkowicz and Higgins [7], spatial ranking of hydrological vulnerability proposed by Chung and Lee [8], analysis of investments in construction by Ustinovichius et al. [9], and multi criteria analysis used for small-scale forestry by Jeffreys [10]. It can be made very clear from the above listed references that, there exist few applications in science and ecological, financial and non-financial units, and rare applications in the related fields of Industrial environment.

The Evaluation of Mixed Data (EVAMIX) method discussed in the present paper is a straightforward and unequivocal way to tackle the mixed (qualitative and quantitative) data for scoring and ranking the available data set combined with analytical hierarchy process. The next section presents combined EVAMIX methodology for decision making in the industrial environment.

\section{Integrated EVAMIX Approach}

The purpose of integrating AHP is done in the present paper to provide a vector of weights expressing the relative importance of alternatives. AHP method helps in structuring the hierarchy of attributes and alternatives for evaluation. It provides assessment of decision makers' evaluation by pair-wise comparisons. The priorities for attributes and alternatives are calculated by maximum eigenvector. Last not but the least synthesis of priorities of the alternatives by criteria is carried out into composite measures to arrive at a set of ratings for the alternatives.

Evaluation of Mixed Data (EVAMIX) method was initially established by Voogd $[3,4]$, and later advocated by Martel and Matarazzo [5]. The novelty of EVAMIX method is that it deals with mixed (qualitative and quantitative) data.

From a procedural point of view, EVAMIX method consists of the seven steps discussed in next section. It commences by identifying unique pairs (criterion-tocriterion) of alternatives. The degree of pair-wise dominance for each pair of alternatives is calculated, as the difference in score received by the higher performing alternative compared to the poorer performing alternative.
The weighted sum of the dominance scores is then assigned to each alternative.

Step I: First a set of objective is identified. Then, various attributes and alternatives are short listed for the given application. Using this information construct a data matrix of $(m \times n)$ size. Where $n$ is number of alternatives and $m$ is the number of relative attributes chosen for selection problem. Next step is to distinguish the ordinal and cardinal criteria out of decision matrix. Attributes are given the linguistic preference, can be converted into its corresponding crisp number as suggested by Chen and Hwang [11].

Step II: Normalising the data set is done in the range of 0 - 1 using linear normalization procedure. The beneficial and non-beneficial attributes are weighted by different equations. For beneficial attributes, normalize the decision matrix using the following equation:

- For beneficial attributes normalize the decision matrix using following equation:

$$
\begin{aligned}
r_{i j}= & {\left[x_{i j}-\min \left(x_{i j}\right)\right] /\left[\max \left(x_{i j}\right)-\min \left(x_{i j}\right)\right] } \\
& (i=1,2, \cdots, m: j=1,2, \cdots, n)
\end{aligned}
$$

- For non-beneficial attributes the above equation can be rewritten as:

$$
\begin{aligned}
& r_{i j}=\left[\max \left(x_{i j}\right)-\left(x_{i j}\right)\right] /\left[\max \left(x_{i j}\right)-\min \left(x_{i j}\right)\right] \\
& \quad(i=1,2, \cdots, m: j=1,2, \cdots, n)
\end{aligned}
$$

According to (1) and (2) in the normalised decision matrix maximum value will always 1 and minimum value equal to 0 .

Step III: Calculate the evaluative differences of $i^{\text {th }}$ alternative on each ordinal and cardinal criterion with respect to other alternatives. This step involves the calculation of differences in criteria values between different alternatives pair-wise. Pair-wise is done based on Analytic Hierarchy Process (AHP) Saaty [12-15] and Xu [16]. It provides a way of breaking down the general data into a hierarch of sub-data, which are easier to evaluate. These comparisons may be taken from actual measurements or from a fundamental scale which reflects the relative strength of preferences introduced by Fechner [17] and further advocated by Turstone [18].

In the pair-wise comparison method, attributes and alternatives are presented in pairs. It is necessary to evaluate individual alternatives. An attribute compared with it is always assigned the value 1 , so the main diagonal entries of the pair-wise comparison matrix are all 1 . The numbers $3,5,7$, and 9 correspond to the verbal judgements "moderate importance", "strong importance", "very strong importance", and "absolute importance" (with 2, 4, 6 , and 8 for compromise between these values). The judgments are given using fundamental scale of AHP. 
- Let $A=\left[a_{i j}\right]$ for all, $i, j=1,2, \cdots, n$ ( $a_{i}$ Vs $a_{j}$ ) denote a square pair-wise comparison matrix. Each entry in the matrix $A$ is positive $\left(a_{i j}>0\right)$ and reciprocal $\left(a_{i j}=1 / a_{j i}, \forall i, j=1,2, \cdots, n\right)$. Using geometric mean method; weights are calculated by following steps.

- Find the relative normalized weight $\left(w_{i}\right)$ of each attributes by geometric means of rows in matrix

$$
A=\left[a_{i j}\right] \text { and represent by } A_{1} \text {. }
$$

- Calculate matrices $A_{2}$ and $A_{3}$. where,

$$
A_{2}=A \times A_{1} \text { and } A_{3}=A_{2} / A_{1},
$$

where, $A_{1}=\left[w_{1}, w_{2}, \cdots, w_{j}\right]^{\mathrm{T}}$

- Determine the maximum Eigen value $\lambda_{\max }$ that is the average of matrix $A_{3}$.

- Calculate the consistency index

$$
\mathrm{CI}=\left(\lambda_{\max }-m\right) /(m-1) .
$$

The smaller the value of CI, the smaller is the deviation form the consistency.

- Obtain the random index (RI) for the number of attributes used in decision making by [12-16].

- Calculate the consistency ratio $\mathrm{CR}=\mathrm{CI} / \mathrm{RI}$. Usually, a $\mathrm{CR}$ of 0.1 or less is considered as acceptable, and it reflects an informed judgment attributable to the knowledge of the analyst regarding the problem under study.

Step IV: Compute the dominance scores of each alternative pair, $\left(i, i^{\prime}\right)$ for all the ordinal and cardinal criteria using the following equations:

$$
\alpha_{i i^{\prime}}=\left[\sum_{j \in O}\left\{W_{j} \operatorname{sgn}\left(r_{i j}-r_{i^{\prime} j}\right)\right\}^{c}\right]^{1 / C}
$$

where

$$
\begin{aligned}
& \operatorname{sgn}\left(r_{i j}-r_{i^{\prime} j}\right)= \begin{cases}+1 & \text { if } r_{i j}>r_{i^{\prime} j} \\
0 & \text { if } r_{i j}=r_{i^{\prime} j} \\
-1 & \text { if } r_{i j}<r_{i^{\prime} j}\end{cases} \\
& \gamma_{i i^{\prime}}=\left[\sum_{j \in C}\left\{W_{j} \operatorname{sgn}\left(r_{i j}-r_{i^{\prime}}\right)\right\}^{c}\right]^{1 / C}
\end{aligned}
$$

The symbol $c$ denotes an arbitrary scaling parameter, for which any arbitrary positive odd number, like 1, 3, $5 \ldots$ may be chosen, $O$ and $C$ are the sets of ordinal and cardinal criteria respectively, and $\alpha_{i i^{\prime}}$ and $\gamma_{i i^{\prime}}$ are the dominance scores for alternative pair, $\left(i, i^{\prime}\right)$ with respect to ordinal and cardinal criteria respectively. In order to be consistence, the same value of scaling parameter $\mathrm{c}$ is used in (5) and (6). It is assumed that the value of c for qualitative evaluation $\alpha_{i i^{\prime}}$ is taken equal to 1 . Evidently, all standardized scores should have the same direction, i.e., a "higher" score should imply a "large" preference. It should be noted that the scores $\gamma_{i i^{\prime}}$ of the quantitative criteria also have to represent "the higher, the better".

Step V: Since $\alpha_{i i^{\prime}}$ and $\gamma_{i i^{\prime}}$ will have different measurement units, a standardization into the same unit is necessary. The standardized dominance scores can be written as:

$$
\delta_{i i^{\prime}}=h\left(\alpha_{i i^{\prime}}\right) \text { and } d_{i i^{\prime}}=h\left(\gamma_{i i^{\prime}}\right)
$$

where $h$ represents a standardization function. The standardized dominance scores can be obtained using three different approaches, i.e., (a) subtractive summation technique, (b) subtracted shifted interval technique, and (c) additive interval technique. The standardized ordinal score $\left(\delta_{i i^{\prime}}\right)$ and cardinal dominance score $\left(d_{i i^{\prime}}\right)$ for the alternative pair, $\left(i, i^{\prime}\right)$ using additive interval technique is calculated by following equations:

Standardized ordinal dominance score

$$
\left(\delta_{i i^{\prime}}\right)=\left(\frac{\alpha_{i i^{\prime}}-\alpha^{-}}{\alpha^{+}-\alpha^{-}}\right)
$$

where $\alpha^{+}\left(\alpha^{-}\right)$is the highest (lowest) ordinal dominance score for the alternative pair, $\left(i, i^{\prime}\right)$.

Standardized cardinal dominance score

$$
\left(d_{i i^{\prime}}\right)=\left(\frac{\gamma_{i i^{\prime}}-\gamma^{-}}{\gamma^{+}-\gamma^{-}}\right)
$$

where $\gamma^{+}\left(\gamma^{-}\right)$is the highest (lowest) cardinal dominance score for the alternative pair, $\left(i, i^{\prime}\right)$.

Step VI: Let us assume that weights $w_{j}$ have quantitative properties. The overall dominance measure $D_{i i^{\prime}}$ for each pair of alternatives $\left(i, i^{\prime}\right)$ is:

$$
D_{i i^{\prime}}=w_{O} \delta_{i i^{\prime}}+w_{C} d_{i i^{\prime}}
$$

where $w_{O}$ is the sum of the weights for the ordinal criteria $\left(w_{O}=\sum_{j \in O} w_{j}\right)$ and $w_{C}$ is the sum of the weights for the cardinal criteria $\left(w_{C}=\sum_{j \in C} w_{j}\right)$. This overall dominance score reflects the degree to which alternative $a_{i}$ dominates alternative $a_{i^{\prime}}$ for the given set of attribute and the weights. In general the measure $D_{i i^{\prime}}$ may be considered as function $K$ of the constituent appraisal scores: $D_{i i^{\prime}}=k\left(s_{i}, s_{i^{\prime}}\right)$. This expression represents a well-known Pairwise comparison problem. Here for each pair $D_{i i^{\prime}}+D_{i^{\prime} i}=1$.

Step VII: Calculate the appraisal score. The appraisal score for $i^{\text {th }}$ alternative $\left(S_{i}\right)$ is computed which gives the final preference of the candidate alternatives. Higher the appraisal score better is the performance of the alternatives. The best alternative is one which has the highest value of the appraisal score.

Appraisal score 


$$
\left(S_{i}\right)=\sum_{i^{\prime}}\left(\frac{D_{i^{\prime} i}}{D_{i i^{\prime}}}\right)^{-1}
$$

The methodology proposed in this paper enables the decision maker to rank the alternatives from best to the worst. The method is able to deal with any number attributes and alternatives by effective mathematical steps. In order to demonstrate and validate the applications of the combined EVAMIX method for industrial environment, following five examples are illustrated.

\section{Examples}

\subsection{Example 1: Automobile Front}

\section{Fender Material Selection}

Proper selection of material is a critical issue for the success of manufacturing aids and competitiveness of the industrial environment. Choice of most appropriate material for a particular engineering application is considered as time consuming and expensive process in past years. Material selection is a step in the process of designing any engineering component. In the context of product design, the main goal of material selection is to minimize cost while meeting product performance goals. Systematic selection of the best material for a given application begins with properties and costs of candidate materials. There exists an ample amount of work being already done on the problem of material selection. EVAMIX is used for material selection of material using weights employed by Chatterjee et al. [2]. Edwards [19] dealt with the decision making for material selection is some important engineering applications. A method is developed by Chen [20] to solve the tool steel material selection problem under fuzzy environment. Jee and Kang [21] utilized two different decision making theories, which are very popular methods. The weighted performance index values for material selection of rocket motors are done by Rajan and Narasimhan [22]. Ermolaeva et al. [23] applied structural optimization method for the optimal choice of foams as a core material for sandwiches with aluminium alloy faces. Material selection carried out by using logical procedure by Rao and Devim [24].
Attempts are made by Chatterjee et al. [25] to solve the material selection problems using TOPSIS and ELECTRE II methods. Shanian and Savadogo [26], applied a non-compensatory compromised approach (ELECTRE IV) for material selection. Weighting factor approach is developed for material selection with combination of non-linear linearization and modified digital logic method by [27]. The life cycle analysis (LCA) based methodology is proposed by Riberio et al. [28] is lagged by deep need of engineering knowledge of all the material and/or technological alternatives for the analysis. A significant effort is needed to identify the "best alternative". The methodology used by Pecas et al. in [29] is a mix between a product development process and a classic material selection process, in a way that combines typical information generated in both processes. In doing so, the selection of materials becomes fully blended in the process evolved with the development of the product, from the concept generation to the industrialization.

The proposed EVAMIX method is quite effective compared with other approaches in terms of mathematical calculations, less time consuming and on hand approach.

Step I: A technically good set of candidate materials is identified and their important properties are identified. As per Riberio [28] and Pecas [29], ordinal (qualitative) and cardinal (quantitative) attributes are distinguished. A pre-set of candidate materials are listed in Table 1.

This set is composed of the current material used (St 1) for the fender construction, two high strength steels, and three Aluminium alloys for which all the engineering properties are known in advance.

Using the set of material from above Table 1, the decision matrix is formed.

$$
D=\left[\begin{array}{ccccccc}
220 & 207 & 7.85 & 7.85 & 32 & 1.50 & 124 \\
350 & 207 & 7.85 & 7.85 & 16 & 1.60 & 197 \\
700 & 207 & 7.85 & 7.85 & 5 & 1.60 & 394 \\
170 & 69 & 2.71 & 2.71 & 24 & 0.70 & 88 \\
190 & 71 & 2.75 & 2.75 & 24 & 0.70 & 107 \\
155 & 70 & 2.74 & 2.74 & 30 & 0.70 & 98
\end{array}\right]
$$

Table 1. Properties of the candidate material of an automobile front fender [29].

\begin{tabular}{lccccccc}
\hline Material & $\begin{array}{c}\text { Yield strength } \\
\text { (MPa) }\end{array}$ & $\begin{array}{c}\text { Ductility (strain at } \\
\text { rupture) (kNm/kg) }\end{array}$ & $\begin{array}{c}\text { Young's } \\
\text { modulus (GPa) }\end{array}$ & $\begin{array}{c}\text { Coefficient } \\
\text { of anisotropy }\end{array}$ & $\begin{array}{c}\text { Hardness } \\
\text { (HV) }\end{array}$ & $\begin{array}{c}\text { Strain hardening } \\
\text { exponent (Nm/kg) }\end{array}$ & $\begin{array}{c}\text { Density } \\
\text { (ton/m }\end{array}$ \\
\hline HX220YD (St 1) & 220 & 32 & 207 & 1.5 & 124 & 0.17 & 7.85 \\
DOCOL600P (St 2) & 350 & 16 & 207 & 1.6 & 197 & 0.15 & 7.85 \\
DOCOL1000P (St 3) & 700 & 5 & 207 & 1.6 & 394 & 0.14 & 7.85 \\
AL6010 (Al 1) & 170 & 24 & 69 & 0.7 & 88 & 0.22 & 2.71 \\
AL2036 (Al 2) & 190 & 24 & 71 & 0.7 & 107 & 0.23 & 2.75 \\
GZ45/30 (Al 3) & 155 & 30 & 70 & 0.7 & 98 & 0.29 \\
\hline
\end{tabular}


A quick analysis of the results obtained by Pecas et al. [29], resulted that the most influent material properties are the yield strength, young's modulus and strain hardening exponent. Hence, in the present paper these three attributes are chosen to be beneficial attributes. For the material to be better in performance if the yield strength is required of higher values than ductility will definitely require being of higher values. The requirement is to select a material with high yield strength, which in other turn says that hardness value must be lower. For the better formability of material into required shape in automobile fender application requires lower coefficient of anisotropy. Thus, it is now clear that hardness and density are non-beneficial attributes.

The importance to each attribute is assigned by Pecas et al. [29]. They also carried pair-wise comparison in order to obtain the engineering property weight $\left(\mathrm{EPW}_{\mathrm{j}}\right)$. To validate the applicability of the method, same weights are taken in the present calculations. The importance or engineering property weights assigned by Pecas et al. are: Yield strength -0.231 , Young's modulus -0.23 , Strain hardening exponent -0.165 , Density -0.14 , Ductility (strain at rupture) - 0.10, Coefficient of anisotropy0.075 and Hardness - 0.06 . Out of seven attributes only yield strength is chosen as ordinal (qualitative) attribute.

Step II: Normalisation is carried using (1) and (2) for beneficial and beneficial attributes respectively. Yield strength, ductility, coefficient of anisotropy, young's modulus, and strain hardening exponent are considered as beneficial attributes. Whereas hardness and density are assumed to be non-beneficial attributes. Table 2 shows the normalized values of listed engineering properties in non-dimensional pattern. Here the value of normalized matrix rang from $0-1$.

Step III: After normalizing the decision matrix, the evaluation differences of the $i^{\text {th }}$ fender material alternative for each ordinal and cardinal criterion with respect to all other material alternatives are calculated. The purpose of method is to show the effectiveness of the scoring and ranking procedure of EVAMIX.

Step IV: The dominance scores for each $(1,2),(1$,
$3), \cdots,(1,6)$ etc. for each $\left(i, i^{\prime}\right)$ pair are computed for ordinal $(\mathrm{C}$, sets of Cardinal attributes) and cardinal $(\mathrm{O}$, sets of Ordinal attributes) attributes using (5) and (6) respectively, and given in Table 3. While calculating the dominance scores, the value of $\mathrm{c}$ is taken equal to 1 .

Step V: Now the standardized dominance is calculated based on the additive interval technique for all the pairs of alternative fender materials using (7) and (8) for the ordinal and cardinal criteria respectively and given in Table 4. It is very clear from the values given in Table 4, that the summation of standardized dominance scores of each $\left(i, i^{\prime}\right)$ and $\left(i^{\prime}, i\right)$ is equal to 1 .

Step VI: The overall dominance score for each alternative fender materials pair $\left(i, i^{\prime}\right)$, is calculated using (9) which shows the degree by which fender material $i$ dominates material $i^{\prime}$. These overall dominance score for all the pairs of alternative fender materials are shown in Table 5.

Step VII: Finally the appraisal score for $i^{\text {th }}$ alternative fender material pair $\left(S_{i}\right)$ is computed using (10).

Higher the appraisal score better is the performance of the alternatives fender material. The appraisal score of each alternative pair in descending order gives the selection of material from best to the worst performing category. The scores and ranking obtained for the best alternative fender material is HX220YD (St 1).

In the present perception of the material ranking, it is clear that the technically the current material i.e., HX220YD (St 1) fulfills the expected quality for the manufacturing of front fender of automobile. The ranking is carried out to eliminate materials with lower technical potential, meaning that any potential advantages of the other materials might permit better economic and environmental performance. The materials $\mathrm{Al} 1$ and $\mathrm{Al} 3$ will be excluded avoiding additional effort on subsequent steps of any further methodology. The other steels (St $2 \&$ St 3) achieve the highest score after St 1. The St 1 is the alternative with lower manufacturing costs derived from the lower material and fixed costs. St 3 for both thickness (estimated and minimum commercially available) having higher manufacturing costs, closely

Table 2. Normalized data of candidate materials.

\begin{tabular}{cccccccr}
\hline & YS & Ductility & YM & COA & Hardness & SHE & Density \\
\hline St 1 & 0.1193 & 1 & 1 & 0.8889 & 0.8824 & 0.2 & 0 \\
St 2 & 0.3578 & 0.3251 & 1 & 1 & 0.6438 & 0.0667 & 0 \\
St 3 & 1 & 0 & 1 & 1 & 0 & 0 & 0 \\
Al 1 & 0.0275 & 0.7037 & 0 & 0 & 0.5333 & 0.6 & 0.9922 \\
Al 2 & 0.0642 & 0.7037 & 0.0145 & 0 & 0.9379 & 0.9673 & 1 \\
Al 3 & 0 & 0.9259 & 0.0072 & 0 & & 0.9922 \\
\hline
\end{tabular}


Table 3. Dominance score of each alternative pair.

\begin{tabular}{ccccccccc}
\hline Pair & $\alpha_{i i^{\prime}}$ & $\gamma_{i i^{\prime}}$ & Pair & $\alpha_{i i^{\prime}}$ & $\gamma_{i i^{\prime}}$ & Pair & $\alpha_{i i^{\prime}}$ & $\gamma_{i i^{\prime}}$ \\
\hline$(1,2)$ & -0.231 & 0.6812 & $(3,1)$ & 0.231 & 0.0888 & $(5,1)$ & -0.231 & 0.3376 \\
$(1,3)$ & -0.231 & 0.6812 & $(3,2)$ & 0.231 & 0 & $(5,2)$ & -0.231 & 0.5745 \\
$(1,4)$ & 0.231 & 0.4324 & $(3,4)$ & 0.231 & 0.1955 & $(5,3)$ & -0.231 & 0.5745 \\
$(1,5)$ & 0.231 & 0.4324 & $(3,5)$ & 0.231 & 0.1955 & $(5,4)$ & 0.231 & 0.616 \\
$(1,6)$ & 0.231 & 0.4324 & $(3,6)$ & 0.231 & 0.1955 & $(5,6)$ & 0.231 & 0.2725 \\
$(2,1)$ & 0.231 & 0.0888 & $(4,1)$ & -0.231 & 0.3376 & $(6,1)$ & -0.231 & 0.3376 \\
$(2,3)$ & -0.231 & 0.7700 & $(4,2)$ & -0.231 & 0.5745 & $(6,2)$ & -0.231 & 0.5745 \\
$(2,4)$ & 0.231 & 0.1955 & $(4,3)$ & -0.231 & 0.5745 & $(6,3)$ & -0.231 & 0.5745 \\
$(2,5)$ & 0.231 & 0.1955 & $(4,5)$ & -0.231 & 0.1540 & $(6,4)$ & -0.231 & 0.7345 \\
$(2,6)$ & 0.231 & 0.1955 & $(4,6)$ & 0.231 & 0.0355 & $(6,5)$ & -0.231 & 0.4975 \\
\hline
\end{tabular}

Table 4. Standardized dominance score of each alternative pair.

\begin{tabular}{ccccccccc}
\hline Pair & $\delta_{i i^{\prime}}$ & $d_{i i^{\prime}}$ & Pair & $\delta_{i i^{\prime}}$ & $d_{i i^{\prime}}$ & Pair & $\delta_{i i^{\prime}}$ & $d_{i i^{\prime}}$ \\
\hline$(1,2)$ & 0 & 0.8846 & $(3,1)$ & 1 & 0.1154 & $(5,1)$ & 0 & 0.4385 \\
$(1,3)$ & 0 & 0.8846 & $(3,2)$ & 1 & 0 & $(5,2)$ & 0 & 0.7462 \\
$(1,4)$ & 1 & 0.5615 & $(3,4)$ & 1 & 0.2538 & $(5,3)$ & 0 & 0.7462 \\
$(1,5)$ & 1 & 0.5615 & $(3,5)$ & 1 & 0.2538 & $(5,4)$ & 1 & 0.8000 \\
$(1,6)$ & 1 & 0.5615 & $(3,6)$ & 1 & 0.2538 & $(5,6)$ & 1 & 0.3538 \\
$(2,1)$ & 1 & 0.1154 & $(4,1)$ & 0 & 0.4385 & $(6,1)$ & 0 & 0.4385 \\
$(2,3)$ & 0 & 1 & $(4,2)$ & 0 & 0.7462 & $(6,2)$ & 0 & 0.7462 \\
$(2,4)$ & 1 & 0.2538 & $(4,3)$ & 0 & 0.7462 & $(6,3)$ & 0 & 0.7462 \\
$(2,5)$ & 1 & 0.2538 & $(4,5)$ & 0 & 0.2000 & $(6,4)$ & 0 & 0.9538 \\
$(2,6)$ & 1 & 0.2538 & $(4,6)$ & 1 & 0.0462 & $(6,5)$ & 0 & 0.6462 \\
\hline
\end{tabular}

Table 5. Overall dominance scores of each alternative pair.

\begin{tabular}{|c|c|c|c|c|c|}
\hline Pair & $D_{i i^{\prime}}$ & Pair & $D_{i i^{\prime}}$ & Pair & $D_{i i^{\prime}}$ \\
\hline$(1,2)$ & 0.6812 & $(3,1)$ & 0.3198 & $(5,1)$ & 0.3376 \\
\hline$(1,3)$ & 0.6812 & $(3,2)$ & 0.2310 & $(5,2)$ & 0.5745 \\
\hline$(1,4)$ & 0.6634 & $(3,4)$ & 0.4265 & $(5,3)$ & 0.5745 \\
\hline$(1,5)$ & 0.6634 & $(3,5)$ & 0.4265 & $(5,4)$ & 0.8470 \\
\hline$(1,6)$ & 0.6634 & $(3,6)$ & 0.4265 & $(5,6)$ & 0.5035 \\
\hline$(2,1)$ & 0.3198 & $(4,1)$ & 0.3376 & $(6,1)$ & 0.3376 \\
\hline$(2,3)$ & 0.7700 & $(4,2)$ & 0.5745 & $(6,2)$ & 0.5745 \\
\hline$(2,4)$ & 0.4265 & $(4,3)$ & 0.5745 & $(6,3)$ & 0.5745 \\
\hline$(2,5)$ & 0.4265 & $(4,5)$ & 0.1540 & $(6,4)$ & 0.7345 \\
\hline$(2,6)$ & 0.4265 & $(4,6)$ & 0.2665 & $(6,5)$ & 0.4975 \\
\hline
\end{tabular}


same to that of the material Al 2. If cost is to be considered for the selection of material than St 1 is doubled than the Al 2.

From all above analysis and from the real application of fender it can be made clear that fender material selection is exclusively based on the manufacturing parameters. For the steel alternatives the use phase importance is higher than the production phase.

The currently used steel St 1 , has the required level of performance on cost for the material and fender production, while $\mathrm{Al} 2$ has the value for fender use and dismantling. The detailed ranking is tabulated in Table 6. Pecas et al. [29] have given further analysis about the selection of best material as per the requirement.

\subsection{Example 2: Selection of Composite Reinforcement}

In order to satisfy the needs of the global economics market, optimized production strategies, expected quality within shorter lead-time and lower life-cycle cost etc. many industries related to composites, are in need for special mathematical tools and methods for improving their product performance as well as to improve competitiveness of the final products. A new methodology is proposed to composites industry, designer and manufacturer in deciding the subsystems as well as composite product system selection. It helps in achieving expected quality and properties of final composite product with the help of integrated systems approach and also a decision-making approach based on the attributes identification. Polymer matrix composite products are generally manufactured using any one of the liquid molding techniques. In any liquid molding processes a preform of reinforced fibers is placed in a closed or open mold and then a liquid polymer resin is injected into the mold to impregnate the preform. When the mold is full, the polymer is cured by a cross-linking reaction to become a rigid solid. Liquid molding processes offer a way to produce high-performance composite products using a rapid process with low labor requirement Rudd et al. [30], Potter [31] gave the material for Resin Transfer molding.
A thorough literature survey reveals that there have been a number of studies associated with variety of composite products manufactured by one of the liquid-molding techniques like resin transfer molding, vacuum-assisted resin transfer molding by various researchers in [32-34]. For all the processes proper selection of subsystems is very important to get the final desired composite structures. Other few papers also give detailed information about various composite product and its interactions between them [35-38].

Composite product selection is carried out by [39] using a technique for order preference by similarity to ideal solution (TOPSIS) and graphical methods (line graph and spider diagram) by considering reasonable attributes in totality. The methodology is a computer assisted MADM method. Ranking and scoring of such composite product system selection should validate by using some other MADM methods. Hence, combined EVAMIX method is used very effectively in the present paper.

To illustrative the ease and logical approach of the proposed methodology an example is discussed for the manufacturing of composite screw rotors for air compressors by resin transfer molding (RTM) process. Following steps will explain the scoring and ranking in detail.

Step I: The peer study resulted into manageable number of candidate reinforcements and their attributes which are listed in Table 7.

The possible candidate reinforcements are chopped glass fibers, chopped carbon fibers and chopped aramid fibers. The minimum required attributes that is responsible for selection of these types of fibers are tensile strength, tensile modulus, volume fraction (\%) and elongation (\%). Decision matrix (D) is formed and ordinal (qualitative) and cardinal (quantitative) criteria are distinguished. Volume fraction can be taken as most influencing ordinal attribute for the selection problem. Using the data from Table 7, decision matrix is formulated as:

$$
D=\left[\begin{array}{cccc}
1600 & 35 & 50 & 4 \\
3528 & 98 & 40 & 1.5 \\
2900 & 18 & 30 & 4.4
\end{array}\right]
$$

Table 6. Appraisal score of alternative material.

\begin{tabular}{cccc}
\hline Fender Mat. & $S_{i}$ additive interval technique & Rank & Rank using MSE \\
\hline St 1 & 0.4055 & 1 & 1 \\
St 2 & 0.1545 & 4 & 2 \\
St 3 & 0.1052 & 5 & 3 \\
Al 1 & 0.0854 & 6 & 6 \\
Al 2 & 0.2165 & 2 & 4 \\
Al 3 & 0.2073 & 3 & 5 \\
\hline
\end{tabular}


Durai et al. [39] carried out the analysis through to obtain the weight vector using maximum eigenvlaue. For sack of validating the effectiveness of the proposed method we have selected the same weights for calculations. The weights assigned are: Tensile strength -0.2662 , Tensile modulus - 0.2517 , Volume fraction- 0.2842 and Elongation-0.1979.

Step II: The increase in volumetric fraction of fiber is significant to improve the specific strength and modulus and hereby reducing the weight of the product. The resin system with high performance provides optimum composite strength and sufficient shear modulus to optimize buckling under compression loads. Normalisation is carried using (1), for beneficial attributes. Tensile strength, tensile modulus, volume fraction and elongation are considered as beneficial attributes. Three stage analysis carried by [39] gave that the attributes selected are all beneficial for the final outcoming product. Thus once the identification is done properly the selection of best alternative will become easy. Table 8 shows the normalized values of listed candidate reinforcements for manufacturing of engineering properties in non-dimensional pattern. Here the value of normalized matrix rang from 0 1.

Step III: After normalizing the decision matrix, the evaluation differences of the $i^{\text {th }}$ candidate reinforcement for each ordinal and cardinal criterion with respect to all other reinforcement alternatives are calculated. The method shows that ranking is still simple using EVAMIX method. Calculations of attributes weights are done using maximum eigenvlaue analysis in [36]. For the sack of comparison weights assigned by the previous researchers are taken to use in the proposed methodology.

Step IV: Resin selected for manufacturing of screw rotor of air compressor must be good to absorb energy and reduce stress concentration. This in turn gives better fracture toughness and ductility to maximize damage tolerance and long-term durability. In composites fibers are strong enough when pulled in the direction of fiber orientation. Furthermore, in composites, higher loads can be safely sustained by the high elongating fibers. Percentage elongation also plays a role in reducing weight of the product. So, compared with other attributes we can say that elongation is the influencing attribute and categorized as ordinal attribute. Table 9 summarized the dominance scores; the value of $\mathrm{c}$ is taken equal to 1 . The dominance scores for candidate reinforcement pair $\left(i, i^{\prime}\right)$ are computed for ordinal and cardinal attributes using (5) and (6) respectively.

Step V: The standardized dominance score is calculated based on the additive interval technique for all the pairs of alternative reinforcement candidate alternatives using (7) and (8) for the ordinal and cardinal criteria respectively and given in Table 10. It is very clear from the values given in Table 10, that the summation of standardized dominance scores of each $\left(i, i^{\prime}\right)$ and $\left(i^{\prime}, i\right)$ is equal to 1 .

Step VI: The overall dominance score for each alternative of candidate reinforcement pair $\left(i, i^{\prime}\right)$, is calculated using (9) which shows the degree by which reinforcement $i$ dominates reinforcement $i^{\prime}$. These overall dominance score for all the pairs of alternative is shown in Table 11.

Step VII: Finally the appraisal score for $i^{\text {th }}$ alternative pair $\left(S_{i}\right)$ is computed using (10). Higher the appraisal score better is the performance of the alternatives reinforcement candidate. The appraisal score of each alternative pair in descending order gives the selection of reinforcement from best to the worst performing category. The scores and ranking is given in Table 12.

The systematic mathematical steps have suggested that the Chopped carbon fiber is the best alternative for and Chopped aramid fiber is the least preferred alternative for the manufacturing of screw rotor of air compressor. Table 13 shows the comparison of ranking and scoring obtained through various MADM methods. Any number of

Table 7. Short listed candidates of reinforcement and their properties [39].

\begin{tabular}{ccccc}
\hline Candidate reinforcements & Tensile strength (MPa) & Tensile modulus (GPa) & Volume fraction (\%) & Elongation (\%) \\
\hline Chopped glass fiber & 1600 & 35 & 50 & 4 \\
Chopped carbon fiber & 3528 & 98 & 40 & 1.5 \\
Chopped aramid fiber & 2900 & 18 & 30 & 4.4 \\
\hline
\end{tabular}

Table 8. Normalized data for candidates of reinforcement.

\begin{tabular}{ccccc}
\hline Candidate reinforcements & Tensile strength (MPa) & Tensile modulus (GPa) & Volume fraction (\%) & Elongation (\%) \\
\hline Chopped glass fiber & 0 & 0.2125 & 1 & 0.8621 \\
Chopped carbon fiber & 1 & 1 & 0.5 & 0 \\
Chopped aramid fiber & 0.6743 & 0 & 0 & 1 \\
\hline
\end{tabular}


Table 9. Dominance score of each alternative pair.

\begin{tabular}{ccc}
\hline Composite Reinforcements Pair & $\alpha_{i i^{\prime}}$ & $\gamma_{i i^{\prime}}$ \\
\hline$(1,2)$ & 0.1979 & -0.2337 \\
$(1,3)$ & -0.1979 & 0.2697 \\
$(2,1)$ & -0.1979 & 0.2337 \\
$(2,3)$ & -0.1979 & 0.8021 \\
$(3,1)$ & 0.1979 & -0.2697 \\
$(3,2)$ & 0.1979 & -0.8021 \\
\hline
\end{tabular}

Table 10. Standard dominance score of each alternative pair.

\begin{tabular}{ccc}
\hline Composite Reinforcement Pair & $\delta_{i i^{\prime}}$ & $d_{i i^{\prime}}$ \\
\hline$(1,2)$ & 1 & 0.3543 \\
$(1,3)$ & 0 & 0.6681 \\
$(2,1)$ & 0 & 0.6457 \\
$(2,3)$ & 0 & 1 \\
$(3,1)$ & 1 & 0.3319 \\
$(3,2)$ & 1 & 0 \\
\hline
\end{tabular}

Table 11. Overall dominance scores of each alternative pair.

\begin{tabular}{cc}
\hline Composite Reinforcement pair & $D_{i{ }^{\prime}}$ \\
\hline$(1,2)$ & 0.4821 \\
$(1,3)$ & 0.5359 \\
$(2,1)$ & 0.5179 \\
$(2,3)$ & 0.8021 \\
$(3,1)$ & 0.4641 \\
$(3,2)$ & 0.1979 \\
\hline
\end{tabular}

Table 12. Appraisal score of composite reinforcement.

\begin{tabular}{lcc}
\hline $\begin{array}{l}\text { Composite } \\
\text { reinforcements }\end{array}$ & $S_{i}$ additive interval technique & Rank \\
\hline Chopped glass fiber & 0.5154 & 2 \\
Chopped carbon fiber & 0.8492 & 1 \\
Chopped aramid fiber & 0.1920 & 3 \\
\hline
\end{tabular}

materials having any number of conflicting attributes can be ranked and scored using EVAMIX method.

The final decision of selecting a set of suitable composite product system after ranking is basis on various factors like environmental aspects, cost, technological aspects etc. The solutions proposed by Durai et al. proposed the TOPSIS and graphical representation in the selection of manufacturing process for developing com- posite product system in an industrial environment. As shown in Table 13 the ranking obtained by various methods are same. Hence, the validity of the EVAMIX method is justified by comparing the performance scores of all the alternative reinforcements.

\subsection{Example 3: Thermal Power Plant Site Selection}

One of the basic inputs of vital importance which has an impact and influenced industrial development and quality is energy. The blooming power generation industry is a sign of growing gross nation. Thermal power generation can be considered as one of the main source of electricity generation. The selection of site for thermal power plant compared with other is difficult as it involves number of factors to be considered for its economic justification; like availability of materials, disposal facilities, space requirements, type of land of site, transportation facility etc.

On the industrial font, emphasis must be placed on the increased with constant effort to reduce energy consumption. Fundamental changes in the process, production and services can affect considerable energy saving without affecting the overall economy. The power plant itself must be useful economically, socially, technically and environmental friendly to the society. Ting and Bing [40] introduced TOPSIS based evaluation of thermal power plant sites. The sitting selection for thermal power plant is supported by few factors;

1) Technical conditions - topography and geology conditions, transportation conditions, load conditions and the quality of resources and environmental conditions;

2) Economical conditions - total investment, annual operating cost and maximum voltage

3) Social conditions - The reasonable site of the thermal power plant selection requires the view of local government and the living conditions of works.

If the site selection is done wrong, it will increase the cost of electricity, and more critical, it will reduce competitiveness in the market to the plant. The potential influence of the irrationality site of the plant to the society and the environment is imponderable. Therefore, the comprehensive evaluation using TOPSIS is carried out for optimizing site selection of thermal power plant site. Few other researchers, such as Yan [41] proposed comprehensive evaluation theory, Jing and Dong [42] used triangular fuzzy numbers for the sitting of thermal power plant, Dong [43] gave application of entropy based fuzzy comprehensive evaluation in sitting of thermal power plant, Dong [44] used grey level analysis in decision making of thermal power plant site, Hai [45] proposed manual application of economic evaluation and Lu et al. [46] used AHP method in the optimal power plant site 
selection. From the literature it is very clear that the method used in the field of evaluation of sitting for the thermal power plant is not analysed with strong mathematical steps. The technological conditions for alternatives are given subjective preference. Ting and Bing [40] have taken some appropriate objective value. If it is required using fuzzy scale we can convert the subjective value into appropriate objective value.

There is a need of some better multi criteria decision making method, to elaborate the behaviour of alternatives with respect to the nature of attributes selected. So, in the present paper EVAMIX is used for the ranking of available sites having combined qualitative and quantitative attribute values. Next section represents the steps to rank the sites for the thermal power plant.

Step I: The feasibility stage of the thermal power plant for sustainable development evaluation must consider the combination of the social, technical and economical benefits. The proposed method enables the combined (ordinal \& cardinal) attributes to be analysed for optimal solution. Six alternative sites and seven attributes are selected for the present example. The example takes six alternatives and seven attributes. The raw data about alternatives are shown in Table 14.

Using these data, decision matrix is formed. The weights are taken same for the comparison purpose. The topography and geology condition is given 0 weights, and this tends to remove this attribute from further analysis.

Step II: By analysis of the normalization carried in Ting and Bing [40], it seems to be clear that only resources and pre-environment conditions is taken as non beneficial attribute.

The technology condition is an influencing criterion for the sitting of power plant. Normalisation is carried using (1) and (2) for beneficial and non-beneficial attributes. Table 15 shows the normalized values of listed sites for thermal power plant. Here always non-dimensional normalization ranges from 0 - 1 .

Step III: After normalizing the decision matrix, the

Table 13. Comparison and ranking of candidates of reinforcement using various methods.

\begin{tabular}{lccccccc}
\hline $\begin{array}{l}\text { Composite } \\
\text { reinforcements }\end{array}$ & $\begin{array}{c}\text { Score using } \\
\text { EVAMIX method }\end{array}$ & Rank & $\begin{array}{c}\text { Score using } \\
\text { TOPSIS method }\end{array}$ & Rank & $\begin{array}{c}\text { Score using } \\
\text { line graph }\end{array}$ & $\begin{array}{c}\text { Rank } \\
\text { spider diagram }\end{array}$ & $\begin{array}{c}\text { Score using } \\
\text { Rank }\end{array}$ \\
\hline Chopped glass fiber & 0.5154 & 2 & 0.3967 & 2 & 0.6522 & 2 \\
Chopped carbon fiber & 0.8492 & 1 & 0.6844 & 1 & 0.8553 & 1 \\
Chopped aramid fiber & 0.1920 & 3 & 0.3604 & 3 & 0.5218 & 3 \\
\hline
\end{tabular}

Table 14. Alternate sites and their evaluation factors [40].

\begin{tabular}{|c|c|c|c|c|c|c|c|}
\hline Site & $\begin{array}{c}\text { Topography } \\
\text { and geology } \\
\text { conditions } \\
\end{array}$ & $\begin{array}{c}\text { Resources and } \\
\text { pro-environment } \\
\text { conditions }\end{array}$ & $\begin{array}{c}\text { Transportation } \\
\text { conditions }\end{array}$ & $\begin{array}{c}\text { Area/ten } \\
\text { thousand } \\
\text { cubic meters }\end{array}$ & $\begin{array}{l}\text { Technology } \\
\text { conditions }\end{array}$ & $\begin{array}{c}\text { Total investment/ } \\
\text { ten million }\end{array}$ & $\begin{array}{c}\text { Review of } \\
\text { local } \\
\text { Governmen }\end{array}$ \\
\hline 1 & 5 & 3.0 & 2 & 43.5 & $\operatorname{Bad}(2)$ & 6 & 6 \\
\hline 2 & 5 & 5.7 & 6 & 429.2 & Very good (6) & 2 & 5 \\
\hline 3 & 5 & 4.75 & 4 & 392 & Very good (6) & 2 & 4 \\
\hline 4 & 5 & 1.2 & 6 & 200 & Good (5) & 2 & 3 \\
\hline 5 & 5 & 3.9 & 4 & 580 & Very good (6) & 2 & 5 \\
\hline 6 & 5 & 4.3 & 2 & 322 & Very good (6) & 2 & 4 \\
\hline
\end{tabular}

Table 15. Normalized data for the site selection.

\begin{tabular}{|c|c|c|c|c|c|c|c|}
\hline Site & $\begin{array}{l}\text { Technology } \\
\text { conditions }\end{array}$ & $\begin{array}{c}\text { Resources and } \\
\text { Pre-Environment } \\
\text { Conditions }\end{array}$ & $\begin{array}{c}\text { Transportation } \\
\text { conditions }\end{array}$ & Area/10,000 m $\mathrm{m}^{3}$ & $\begin{array}{l}\text { Topography } \\
\text { and geology } \\
\text { conditions } \\
\end{array}$ & $\begin{array}{c}\text { Total } \\
\text { Investment }\end{array}$ & $\begin{array}{l}\text { Review of } \\
\text { local govt. }\end{array}$ \\
\hline 1 & 0 & 0.6 & 0 & 0 & 1 & 1 & 6 \\
\hline 2 & 1 & 0 & 1 & 0.7189 & 1 & 0 & 0.6667 \\
\hline 3 & 1 & 0.2111 & 0.5 & 0.6496 & 1 & 0 & 0.3333 \\
\hline 4 & 0.75 & 1 & 1 & 0.2917 & 1 & 0 & 0 \\
\hline 5 & 1 & 0.4 & 0.5 & 1 & 1 & 0 & 0.6667 \\
\hline 6 & 1 & 0.3111 & 0 & 0.5191 & 1 & 0 & 0.3333 \\
\hline
\end{tabular}


evaluation differences of the $i^{\text {th }}$ site ordinal and cardinal criterion with respect to all other site alternatives are calculated. The mathematical steps of EVAMIX in the present paper are clearer than the method used by [40]. The method shows that ranking is still simple using EVAMIX method. Weights are taken from [40] for comparison of results and listed as, Topology and geology conditions - 0 , resources and pre-environment conditions - 0.32, transportation conditions - 0.41 , area0.32 , technology conditions - 0.37 , total investment0.37 and review of local government -0.32 . The weights assigned are taken same as that of the previous researchers. It is also clear that the effect of topology and geology conditions is assumed to null.

Step IV: Sitting selection for thermal power plant is done by taking first attribute to be null and technology conditions as influencing attribute. Using (5) and (6) respectively, dominance scores for all candidate sites are calculated and given in Table 16.

Step V: The standardized dominance is calculated based on the additive interval technique for all the pairs of alternative site using (7) and (8) for the ordinal and cardinal criteria respectively and given in Table 17.

Step VI: The overall dominance score for each alternative of site for thermal power plant pair $\left(i, i^{\prime}\right)$, is calculated using (9) which shows the degree by which reinforcement $i$ dominates reinforcement $i^{\prime}$. These scores obtained using (9) show the degree by which reinforcement $i$ dominates reinforcement $i^{\prime}$. These overall dominance score for all the pairs of alternative is shown in Table 18.

Step VII: Finally the appraisal score for $i^{\text {th }}$ alternative pair $\left(S_{i}\right)$ is computed using (10).

Higher the appraisal score better is the site for the thermal power plant location. The scores and ranking is given in Table 19.

Table 16. Dominance score of each alternative pair.

\begin{tabular}{ccccccccc}
\hline Pair & $\alpha_{i i^{\prime}}$ & $\gamma_{i i^{\prime}}$ & Pair & $\alpha_{i i^{\prime}}$ & $\gamma_{i i^{\prime}}$ & Pair & $\alpha_{i i^{\prime}}$ & $\gamma_{i i^{\prime}}$ \\
\hline$(1,2)$ & -0.37 & 0.28 & $(3,1)$ & 0.37 & -0.28 & $(5,1)$ & -0.37 & -0.28 \\
$(1,3)$ & -0.37 & 0.28 & $(3,2)$ & 0.37 & -0.73 & $(5,2)$ & -0.37 & 0.23 \\
$(1,4)$ & 0.37 & -0.36 & $(3,4)$ & 0.37 & -0.09 & $(5,3)$ & -0.37 & 0.96 \\
$(1,5)$ & 0.37 & 0.28 & $(3,5)$ & 0.37 & -0.96 & $(5,4)$ & 0.37 & -0.09 \\
$(1,6)$ & 0.37 & 0.69 & $(3,6)$ & 0.37 & 0.41 & $(5,6)$ & 0.37 & 1.37 \\
$(2,1)$ & 0.37 & -0.28 & $(4,1)$ & -0.37 & 0.36 & $(6,1)$ & -0.37 & -0.69 \\
$(2,3)$ & -0.37 & 0.73 & $(4,2)$ & -0.37 & -0.32 & $(6,2)$ & -0.37 & -0.73 \\
$(2,4)$ & 0.37 & 0.32 & $(4,3)$ & -0.37 & 0.09 & $(6,3)$ & -0.37 & -0.41 \\
$(2,5)$ & 0.37 & -0.23 & $(4,5)$ & -0.37 & 0.09 & $(6,4)$ & -0.37 & -0.09 \\
$(2,6)$ & 0.37 & 0.73 & $(4,6)$ & 0.37 & 0.09 & $(6,5)$ & -0.37 & -1.37 \\
\hline
\end{tabular}

Table 17. Standardized dominance score of each alternative pair.

\begin{tabular}{cccccccccc}
\hline Pair & $\delta_{i i^{\prime}}$ & $d_{i i^{\prime}}$ & Pair & $\delta_{i i^{\prime}}$ & $d_{i i^{\prime}}$ & Pair & $\delta_{i i^{\prime}}$ & $d_{i i^{\prime}}$ \\
\hline$(1,2)$ & 0 & 0.6022 & $(3,1)$ & 1 & 0.3978 & $(5,1)$ & 0 & 0.3978 \\
$(1,3)$ & 0 & 0.6022 & $(3,2)$ & 1 & 0.2336 & $(5,2)$ & 0 & 0.5839 \\
$(1,4)$ & 1 & 0.3686 & $(3,4)$ & 1 & 0.4672 & $(5,3)$ & 0 & 0.8504 \\
$(1,5)$ & 1 & 0.6022 & $(3,5)$ & 1 & 0.1496 & $(5,4)$ & 1 & 0.4671 \\
$(1,6)$ & 1 & 0.7518 & $(3,6)$ & 1 & 0.6496 & $(5,6)$ & 1 & 1 \\
$(2,1)$ & 1 & 0.3978 & $(4,1)$ & 0 & 0.6314 & $(6,1)$ & 0 & 0.2482 \\
$(2,3)$ & 0 & 0.7664 & $(4,2)$ & 0 & 0.3832 & $(6,2)$ & 0 & 0.2336 \\
$(2,4)$ & 1 & 0.6168 & $(4,3)$ & 0 & 0.5328 & $(6,3)$ & 0 & 0.3504 \\
$(2,5)$ & 1 & 0.4161 & $(4,5)$ & 0 & 0.5328 & $(6,4)$ & 0 & 0.4672 \\
$(2,6)$ & 1 & 0.7664 & $(4,6)$ & 1 & 0.5328 & $(6,5)$ & 0 & 0 \\
\hline
\end{tabular}


Table 18. Overall dominance scores of each alternative pair.

\begin{tabular}{cccccc}
\hline Pair & $D_{i i^{\prime}}$ & Pair & $D_{i i^{\prime}}$ & Pair & $D_{i^{\prime}}$ \\
\hline$(1,2)$ & 1.0478 & $(3,1)$ & 1.0622 & $(5,1)$ & 1.062 \\
$(1,3)$ & 1.0478 & $(3,2)$ & 0.5914 & $(5,2)$ & 1.2011 \\
$(1,4)$ & 0.6414 & $(3,4)$ & 1.1828 & $(5,3)$ & 1.6646 \\
$(1,5)$ & 1.0478 & $(3,5)$ & 0.4454 & $(5,4)$ & 1.1823 \\
$(1,6)$ & 1.3082 & $(3,6)$ & 1.3154 & $(5,6)$ & 1.9250 \\
$(2,1)$ & 1.0622 & $(4,1)$ & 1.4686 & $(6,2)$ & 0.8018 \\
$(2,3)$ & 1.5185 & $(4,2)$ & 0.6668 & 0.5914 \\
$(2,4)$ & 1.4432 & $(4,3)$ & 0.9271 & $(6,3)$ & 0.7946 \\
$(2,5)$ & 0.9089 & $(4,6)$ & 0.9272 & $(6,4)$ & $(6,5)$ \\
$(2,6)$ & 1.5186 & & 0.9272 & 0.1850 \\
\hline
\end{tabular}

Table 19. Appraisal score of each alternative site for thermal power plant.

\begin{tabular}{ccc}
\hline Sites & $S_{i}$ additive interval technique & Rank \\
\hline 1 & 0.1682 & 3 \\
2 & 0.2817 & 2 \\
3 & 0.1152 & 5 \\
4 & 0.1555 & 4 \\
5 & 0.3459 & 1 \\
6 & 0.0586 & 6 \\
\hline
\end{tabular}

As per the evaluation process followed by Ting and Bing [40], site no. 2 and 5 are equally good based on the values obtained for relative adjacent degree. The proposed methodology (EVAMIX) cleared the tie between selections of site no. 2 and site no. 5. The appraisal scores for six sites given in Table 19 reveal that site no. 2 is the first choice for thermal power plant. Site no. 5 become second choice according as some difference reflects from resource conditions, transportation conditions and area available for the sitting. The comparison of different sites about the location of power plant by the method of EVAMIX finds the optimal solution and helps decision maker in selecting the best site.

\subsection{Example 4: Evaluation of AGV Fleet Operation at Port Container Terminal}

Port container terminal provides a service of container handling, more precisely, unloading containers from ships onto inland vehicles (typically trucks and trains), and vice versa, with the purpose of distributing containers to the end users. Terminals are equipped with corresponding reloading machinery and with opened storage areas dedicated for shorter or longer storage of loaded or empty containers. In the process of planning the con- tainer handling at port container terminals, arrivals of container ships cannot be precisely defined in time and they represent a group of approximately known values mentioned by Danijela et al. [47]. One of the ways to improve the total productivity of a container terminal (to reduce ship turnaround times) is to increase the automation of the cargo handling and transport, and to use the most efficient container handling scenario. Advantages in the fields of electronic, automation, information technologies and sensors are enabling a development of fully automated container terminals discussed by loannou [48]. In the studied container terminal the quay cranes were unloading containers from the ship; the containers were further transported to the storage areas by automated guided vehicles (AGVs).

Ports are an important link in the logistics chain so the level of port efficiency affects to a large extent the country's competitiveness, since port efficiency results in lower tariffs for exports which, in turn, favour the competitiveness of country products in international markets. Therefore, in order to keep a competitive position in those markets, the countries need to work on the factors that affect the efficiency of their ports and draw continuous comparisons on the degree of efficiency among them and with the ports of other regions [49].

From the literature it is found that the DEA and its various models are only applied for the efficiency evaluation in the field of port container terminals and similar situations. Efficiency measurement of seaport with DEA is proposed by Barrows [50]. Cullinane and Song [51] used DEA windows analysis to container port production efficiency. Cullinane and Wang [52] also gave the application of DEA. Kaisar [53] measured efficiency of US port is carried out using DEA. Analysis of AGV systems for two container yard system is done in Liu and Jula [54]. Evaluation of international container terminals using DEA is proposed by Min and Park in [55]. Pjevcevic 
and Vukadinovic in [56] characterization of the AGV dispatching rules is discussed.

It is clear from evaluation of port container systems required some simple but still logical MCDM method to be applied. The proposed combined EVAMIX methodology, deals with evaluation efficiencies of handling of containers that arrive at port. This analysis evaluated 12 scenarios for containers dispatching from Berth to storage areas. The purpose of evaluation is to rank these 12 scenarios. Four attributes selected are number of employed AGVs, AGVs active rate, reciprocal value of the number of containers in the queue and number of served containers. Next sections describe the sequential procedure for ranking of scenarios.

Step I: In the illustrative example the aim is to show the effectiveness of number of employed AGVs and dispatching rule on container handling i.e., number of containers in queue, AGV utilization etc. using AHP and EVAMIX methods. Only reciprocal value of the number of containers in the queue is an ordinal attribute. Other three are categorised under cardinal attributes. 12 alternative scenarios and 4 are analysed to calculate the weights using AHP method. Table 20 shows the raw data for scenario selection.

Step II: To improve the total productivity of a container terminal, the first requirement is to reduce the ship turnaround times. The entire process is depending on the effectiveness of unloading containers in the queue waiting to be served by AGVs. Normalization is carried out using (1) and (2) for beneficial and non-beneficial attributes respectively. Table 21 shows the normalized values of scenarios under selection problem.

Step III: After normalizing the decision matrix, the evaluation differences of the $i^{\text {th }}$ site ordinal and cardi- nal criterion with respect to all other scenarios are calculated. The mathematical steps of combined EVAMIX given in the present paper have maximum impact on selection procedure compared with any other methods used by the previous researchers. The method shows that ranking is still simple using EVAMIX method. The reciprocal value of the number of containers in the queue is taken as ordinal attributes which always shows the effecttiveness of port terminal. As the length of queue should be low enough to show better dispatching through the port it is non-beneficial attribute for the alternative port terminals.

Pair-wise comparison is done by considering the relative importance of each attribute compared to other.

Matrix $A$ is relative importance matrix.

$$
A=\left[\begin{array}{cccc}
1 & 3 & 2 & 2 \\
1 / 3 & 1 & 2 & 1 \\
1 / 2 & 1 / 2 & 1 & 1 \\
1 / 2 & 1 & 1 & 1
\end{array}\right]
$$

Number of AGVs is moderately more important attribute than the AGV active rate. So, a relative importance value of 3 is assigned to number of AGVs over AGV active rate and assigned the value $1 / 3$ to AGV active rate over number of AGVs. In this way a complete matrix is $A$ formed. As explained in section 2, $A_{1}$, $A_{2}$ and $A_{3}$ matrices are calculated:

$$
A_{1}=\left[\begin{array}{l}
0.4316 \\
0.2095 \\
0.1640 \\
0.1950
\end{array}\right] \quad A_{2}=\left[\begin{array}{l}
1.7780 \\
0.8763 \\
0.6795 \\
0.7842
\end{array}\right] \quad A_{3}=\left[\begin{array}{l}
4.1199 \\
4.1823 \\
4.1442 \\
4.0221
\end{array}\right]
$$

Table 20. Data of scenario of AGV fleet operation [47].

\begin{tabular}{ccccc}
\hline Scenario & $\begin{array}{c}\text { Number of efficiency } \\
\text { employed AGVs }\end{array}$ & $\begin{array}{c}\text { AGVs active } \\
\text { rate }\end{array}$ & $\begin{array}{c}\text { Reciprocal value of the number } \\
\text { of containers in the queue }\end{array}$ & $\begin{array}{c}\text { Number of served } \\
\text { containers }\end{array}$ \\
\hline Scenario 1 & 18 & 0.94 & 0.0068 & 1554 \\
Scenario 2 & 20 & 0.94 & 0.0095 & 1613 \\
Scenario 3 & 23 & 0.92 & 0.0132 & 1712 \\
Scenario 4 & 18 & 0.97 & 0.0075 & 1575 \\
Scenario 5 & 20 & 0.96 & 0.0097 & 1625 \\
Scenario 6 & 23 & 0.95 & 0.0161 & 1711 \\
Scenario 7 & 18 & 0.93 & 0.0127 & 1629 \\
Scenario 8 & 20 & 0.92 & 0.0204 & 1685 \\
Scenario 9 & 23 & 0.91 & 0.0714 & 1774 \\
Scenario 10 & 18 & 1.00 & 0.0061 & 1531 \\
Scenario 11 & 20 & 1.00 & 0.0078 & 1607 \\
Scenario 12 & 23 & 1.00 & 0.0095 & 1662 \\
\hline
\end{tabular}


The value of maximum eigenvector is calculated, $\lambda_{\text {max }}=16.4686 / 4=4.1171$. Consistency index is equal to $\mathrm{CI}=\left(\lambda_{\max }-4\right) / 3=0.0390$. The random index value is 0.90 , which turns to the Consistency ratio $=$

$\mathrm{CR}=\mathrm{CI} / 0.90=0.0434$, which is much less than the allowable $\mathrm{CR}$ value of 0.1 . Hence, we can conclude that a good consistency in the relative importance matrix formation is maintained.

Step IV: Number of AGVs employed and the AGV active rate, the time of $\mathrm{AGV}$ in use for both empty and full move are considered to be non-beneficial attributes. The number of containers in the queue to be unloaded from the ship by quay cranes, waiting for AGVs to be transferred to one of the storage areas and number of served containers which are moved from Berth to storage areas are taken as beneficial attributes. The dominance scores of each alternative scenario pair are calculated using (5) and (6) respectively. The values of dominance scores for all alternative scenarios are tabulated in Tables 22(a) and (b).

Step V: The standardized dominance is calculated based on the additive interval technique for all the pairs of alternative scenarios using (7) and (8) for the ordinal and cardinal criteria respectively and given in Tables 23(a) and (b).

Step VI: The overall dominance score for each alternative of scenarios for all pair $\left(i, i^{\prime}\right)$, is calculated using (9) which shows the degree by which scenario $i$ dominates scenario $i^{\prime}$. These overall dominance score for all the pairs of alternative is shown in Table 24.

Step VII: Finally the appraisal score for $i^{\text {th }}$ alternative pair $\left(S_{i}\right)$ is computed using (10). Higher the appraisal score better is the scenario for port terminal. The scores and ranking is given in Table 25. The results gave Scenario 7, Scenario 8, and Scenario 9 at first three positions in selection process and Scenario 12 with lowest score at last position in selection. The ranking obtained comprehends with the results obtained by previous researches.

The analysis of the simulation results dispatching rule followed in 7,8 and 9 alternatives indicated that the smallest distance rule provided the best scenario regarding the number of served containers and the number of containers in the queue, under the assumption about the number of employed AGVs. Analysis of AGVs in [47] idle rate and AGVs active rates showed that the values of these rates were very close among scenario, thus, it was not possible to make a decision of which scenario could be considered the best.

The proposed integrated method gave the scenario to be best with smallest dispatching distance with clearly distinguishing scores. The scenario with largest distance i.e., 10, 11 and 12 are ranked to be last in the selection. In simple terms the smallest distance with minimum number of AGVs required to be employed is the best scenario for this application. Whereas the largest distance with maximum number of AGVs employed is ranked to be the last.

\subsection{Example 5: Selection of Facility Layout Design}

In this section, an example is illustrated for the efficiency and effectiveness measurement of the facility layout design for an anonymous leading IC packaging company located in Kaohsiung as discussed by Yang and Kuo [57].

Table 21. Normalized data of scenario of AGV fleet operation.

\begin{tabular}{ccccc}
\hline Scenario & $\begin{array}{c}\text { Number of efficiency } \\
\text { employed AGV }\end{array}$ & $\begin{array}{c}\text { AGV active } \\
\text { rate }\end{array}$ & $\begin{array}{c}\text { Reciprocal value of the number of } \\
\text { containers in the queue }\end{array}$ & $\begin{array}{c}\text { Number of served } \\
\text { containers }\end{array}$ \\
\hline Scenario 1 & 1 & 0.6667 & 0.0107 & 0.0947 \\
Scenario 2 & 0.6 & 0.6667 & 0.0521 & 0.3374 \\
Scenario 3 & 0 & 0.8889 & 0.1087 & 0.7449 \\
Scenario 4 & 1 & 0.3333 & 0.0214 & 0.1811 \\
Scenario 5 & 0.6 & 0.4444 & 0.0551 & 0.3868 \\
Scenario 6 & 0 & 0.5556 & 0.1531 & 0.7407 \\
Scenario 7 & 1 & 0.7778 & 0.1011 & 0.4033 \\
Scenario 8 & 0.6 & 0.8889 & 0.2190 & 0.6337 \\
Scenario 9 & 0 & 1 & 1 & 1 \\
Scenario 10 & 1 & 0 & 0 & 0 \\
Scenario 11 & 0.6 & 0 & 0.0260 & 0.3128 \\
Scenario 12 & 0 & 0 & 0.0521 & 0.5391 \\
\hline
\end{tabular}


Table 22. (a) Dominance score of each alternative pair of scenario of AGV fleet operation; (b) Dominance score of each alternative pair of scenario of AGV fleet operation.

(a)

\begin{tabular}{|c|c|c|c|c|c|c|c|c|}
\hline Pair & $\alpha_{i i^{\prime}}$ & $\gamma_{i i^{\prime}}$ & Pair & $\alpha_{i i^{\prime}}$ & $\gamma_{i i^{\prime}}$ & Pair & $\alpha_{i i^{\prime}}$ & $\gamma_{i i^{\prime}}$ \\
\hline$(1,2)$ & -0.1640 & 0.2366 & $(3,1)$ & 0.1640 & -0.0271 & $(5,1)$ & 0.1640 & -0.4461 \\
\hline$(1,3)$ & -0.1640 & 0.0271 & $(3,2)$ & 0.1640 & -0.0271 & $(5,2)$ & 0.1640 & -0.0145 \\
\hline$(1,4)$ & -0.1640 & 0.0145 & $(3,4)$ & 0.1640 & -0.0271 & $(5,3)$ & -0.1640 & 0.0271 \\
\hline$(1,5)$ & -0.1640 & 0.4461 & $(3,5)$ & 0.1640 & -0.0271 & $(5,4)$ & 0.1640 & -0.0271 \\
\hline$(1,6)$ & -0.1640 & 0.4461 & $(3,6)$ & -0.1640 & 0.4045 & $(5,6)$ & -0.1640 & 0.0271 \\
\hline$(1,7)$ & -0.1640 & -0.4045 & $(3,7)$ & 0.1640 & -0.0271 & $(5,7)$ & -0.1640 & -0.8361 \\
\hline$(1,8)$ & -0.1640 & 0.0271 & $(3,8)$ & -0.1640 & -0.2366 & $(5,8)$ & -0.1640 & -0.4045 \\
\hline$(1,9)$ & -0.1640 & 0.0271 & $(3,9)$ & -0.1640 & -0.4045 & $(5,9)$ & -0.1640 & 0.0271 \\
\hline$(1,10)$ & 0.1640 & 0.4045 & $(3,10)$ & 0.1640 & -0.0271 & $(5,10)$ & 0.1640 & -0.0271 \\
\hline$(1,11)$ & -0.1640 & 0.4461 & $(3,11)$ & 0.1640 & -0.0271 & $(5,11)$ & 0.1640 & 0.4045 \\
\hline$(1,12)$ & -0.1640 & 0.4461 & $(3,12)$ & 0.1640 & 0.4045 & $(5,12)$ & 0.1640 & 0.4461 \\
\hline$(2,1)$ & +0.1640 & -0.2366 & $(4,1)$ & 0.1640 & -0.0145 & $(6,1)$ & 0.1640 & -0.4461 \\
\hline$(2,3)$ & -0.1640 & 0.0271 & $(4,2)$ & -0.1640 & 0.0271 & $(6,2)$ & 0.1640 & -0.4461 \\
\hline$(2,4)$ & 0.1640 & -0.0271 & $(4,3)$ & -0.1640 & 0.0271 & $(6,3)$ & 0.1640 & -0.4045 \\
\hline$(2,5)$ & -0.1640 & 0.0145 & $(4,5)$ & -0.1640 & 0.0271 & $(6,4)$ & 0.1640 & -0.0271 \\
\hline$(2,6)$ & -0.1640 & 0.4461 & $(4,6)$ & -0.1640 & 0.0271 & $(6,5)$ & 0.1640 & -0.0271 \\
\hline$(2,7)$ & -0.1640 & -0.8361 & $(4,7)$ & -0.1640 & -0.4045 & $(6,7)$ & 0.1640 & -0.4461 \\
\hline$(2,8)$ & -0.1640 & -0.4045 & $(4,8)$ & -0.1640 & 0.0271 & $(6,8)$ & -0.1640 & -0.4461 \\
\hline$(2,9)$ & -0.1640 & 0.0271 & $(4,9)$ & -0.1640 & 0.0271 & $(6,9)$ & -0.1640 & -0.4045 \\
\hline$(2,10)$ & -0.1640 & -0.0271 & $(4,10)$ & -0.1640 & 0.4045 & $(6,10)$ & 0.1640 & -0.0271 \\
\hline$(2,11)$ & 0.1640 & 0.4045 & $(4,11)$ & -0.1640 & 0.4461 & $(6,11)$ & 0.1640 & -0.0271 \\
\hline$(2,12)$ & 0 & 0.4461 & $(4,12)$ & -0.1640 & 0.4461 & $(6,12)$ & 0.1640 & 0.4045 \\
\hline
\end{tabular}

(b)

\begin{tabular}{|c|c|c|c|c|c|c|c|c|}
\hline Pair & $\alpha_{i i^{\prime}}$ & $\gamma_{i i^{\prime}}$ & Pair & $\alpha_{i i^{\prime}}$ & $\gamma_{i i^{\prime}}$ & Pair & $\alpha_{i i^{\prime}}$ & $\gamma_{i i^{\prime}}$ \\
\hline$(7,1)$ & 0.1640 & 0.4045 & $(9,1)$ & 0.1640 & -0.0271 & $(11,1)$ & 0.1640 & -0.4461 \\
\hline$(7,2)$ & 0.1640 & 0.8361 & $(9,2)$ & 0.1640 & -0.0271 & $(11,2)$ & -0.1640 & -0.4045 \\
\hline$(7,3)$ & -0.1640 & 0.0271 & $(9,3)$ & 0.1640 & 0.4045 & $(11,3)$ & -0.1640 & 0.0271 \\
\hline$(7,4)$ & 0.1640 & 0.4045 & $(9,4)$ & 0.1640 & -0.0271 & $(11,4)$ & 0.1640 & -0.4461 \\
\hline$(7,5)$ & 0.1640 & 0.8361 & $(9,5)$ & 0.1640 & -0.0271 & $(11,5)$ & 0.1640 & -0.4045 \\
\hline$(7,6)$ & -0.1640 & 0.4461 & $(9,6)$ & 0.1640 & 0.4045 & $(11,6)$ & 0.1640 & 0.0271 \\
\hline$(7,8)$ & -0.1640 & 0.0271 & $(9,7)$ & 0.1640 & -0.0271 & $(11,7)$ & -0.1640 & -0.8361 \\
\hline$(7,9)$ & -0.1640 & 0.0271 & $(9,8)$ & 0.1640 & -0.0271 & $(11,8)$ & -0.1640 & -0.4045 \\
\hline$(7,10)$ & 0.1640 & 0.4045 & $(9,10)$ & 0.1640 & -0.0271 & $(11,9)$ & -0.1640 & 0.0271 \\
\hline$(7,11)$ & 0.1640 & 0.8361 & $(9,11)$ & 0.1640 & -0.0271 & $(11,10)$ & 0.1640 & -0.2366 \\
\hline$(7,12)$ & 0.1640 & 0.4461 & $(9,12)$ & 0.1640 & 0.4045 & $(11,12)$ & -0.1640 & 0.2366 \\
\hline$(8,1)$ & 0.1640 & -0.0271 & $(10,1)$ & -0.1640 & -0.4045 & $(12,1)$ & 0.1640 & -0.4461 \\
\hline$(8,2)$ & 0.1640 & 0.4045 & $(10,2)$ & -0.1640 & 0.0271 & $(12,2)$ & 0 & -0.4461 \\
\hline$(8,3)$ & 0.1640 & 0.2366 & $(10,3)$ & -0.1640 & 0.0271 & $(12,3)$ & -0.1640 & -0.4045 \\
\hline$(8,4)$ & 0.1640 & -0.0271 & $(10,4)$ & 0.1640 & -0.4045 & $(12,4)$ & 0.1640 & -0.4461 \\
\hline$(8,5)$ & 0.1640 & 0.4045 & $(10,5)$ & -0.1640 & 0.0271 & $(12,5)$ & -0.1640 & -0.4461 \\
\hline$(8,7)$ & 0.1640 & 0.4461 & $(10,6)$ & -0.1640 & 0.0271 & $(12,6)$ & -0.1640 & -0.4045 \\
\hline$(8,8)$ & 0.1640 & -0.0271 & $(10,7)$ & -0.1640 & -0.4045 & $(12,7)$ & 0.1640 & -0.4461 \\
\hline$(8,9)$ & -0.1640 & 0.0271 & $(10,8)$ & -0.1640 & 0.0271 & $(12,8)$ & 0.1640 & -0.8361 \\
\hline$(8,10)$ & 0.1640 & -0.0271 & $(10,9)$ & -0.1640 & 0.0271 & $(12,9)$ & 0.1640 & -0.4045 \\
\hline$(8,11)$ & 0.1640 & 0.4045 & $(10,11)$ & 0.1640 & 0.2366 & $(12,10)$ & 0.1640 & -0.2366 \\
\hline$(8,12)$ & 0.1640 & 0.8361 & $(10,12)$ & -0.1640 & 0.2366 & $(12,11)$ & 0.1640 & -0.2366 \\
\hline
\end{tabular}


Table 23. (a) Standard dominance score of each alternative pair of scenario of AGV fleet operation; (b) Standard dominance score of each alternative pair of scenario of AGV fleet operation.

(a)

\begin{tabular}{|c|c|c|c|c|c|c|c|c|}
\hline Pair & $\delta_{i i^{\prime}}$ & $d_{i i^{\prime}}$ & Pair & $\delta_{i i^{\prime}}$ & $d_{i i^{\prime}}$ & Pair & $\delta_{i i^{\prime}}$ & $d_{i i^{\prime}}$ \\
\hline$(1,2)$ & 0 & 0.6415 & $(3,1)$ & 1 & 0.4838 & $(5,1)$ & 1 & 0.2332 \\
\hline$(1,3)$ & 0 & 0.5162 & $(3,2)$ & 1 & 0.4838 & $(5,2)$ & 1 & 0.4913 \\
\hline$(1,4)$ & 0 & 0.5087 & $(3,4)$ & 1 & 0.4838 & $(5,3)$ & 0 & 0.5162 \\
\hline$(1,5)$ & 0 & 0.7668 & $(3,5)$ & 1 & 0.4838 & $(5,4)$ & 1 & 0.4838 \\
\hline$(1,6)$ & 0 & 0.7668 & $(3,6)$ & 0 & 0.7419 & $(5,6)$ & 0 & 0.5162 \\
\hline$(1,7)$ & 0 & 0.2581 & $(3,7)$ & 1 & 0.4838 & $(5,7)$ & 0 & 0.0000 \\
\hline$(1,8)$ & 0 & 0.5162 & $(3,8)$ & 0 & 0.3585 & $(5,8)$ & 0 & 0.2581 \\
\hline$(1,9)$ & 0 & 0.5162 & $(3,9)$ & 0 & 0.2581 & $(5,9)$ & 0 & 0.5162 \\
\hline$(1,10)$ & 1 & 0.7419 & $(3,10)$ & 1 & 0.4838 & $(5,10)$ & 1 & 0.4838 \\
\hline$(1,11)$ & 0 & 0.7668 & $(3,11)$ & 1 & 0.4838 & $(5,11)$ & 1 & 0.7419 \\
\hline$(1,12)$ & 0 & 0.7668 & $(3,12)$ & 1 & 0.7419 & $(5,12)$ & 1 & 0.7668 \\
\hline$(2,1)$ & 1 & 0.3585 & $(4,1)$ & 1 & 0.4913 & $(6,1)$ & 1 & 0.2332 \\
\hline$(2,3)$ & 0 & 0.5162 & $(4,2)$ & 0 & 0.5162 & $(6,2)$ & 1 & 0.2332 \\
\hline$(2,4)$ & 1 & 0.4838 & $(4,3)$ & 0 & 0.5162 & $(6,3)$ & 1 & 0.2581 \\
\hline$(2,5)$ & 0 & 0.5087 & $(4,5)$ & 0 & 0.5162 & $(6,4)$ & 1 & 0.4838 \\
\hline$(2,6)$ & 1 & 0.7668 & $(4,6)$ & 0 & 0.5162 & $(6,5)$ & 1 & 0.4838 \\
\hline$(2,7)$ & 1 & 0.0000 & $(4,7)$ & 0 & 0.2581 & $(6,7)$ & 1 & 0.2332 \\
\hline$(2,8)$ & 1 & 0.2581 & $(4,8)$ & 0 & 0.5162 & $(6,8)$ & 0 & 0.2332 \\
\hline$(2,9)$ & 1 & 0.5162 & $(4,9)$ & 0 & 0.5162 & $(6,9)$ & 0 & 0.2581 \\
\hline$(2,10)$ & 0 & 0.4838 & $(4,10)$ & 1 & 0.7419 & $(6,10)$ & 1 & 0.4838 \\
\hline$(2,11)$ & 1 & 0.7419 & $(4,11)$ & 0 & 0.7668 & $(6,11)$ & 1 & 0.4838 \\
\hline$(2,12)$ & 0.5 & 0.7668 & $(4,12)$ & 0 & 0.7668 & $(6,12)$ & 1 & 0.7419 \\
\hline
\end{tabular}

(b)

\begin{tabular}{ccccccccc}
\hline Pair & $\delta_{i i^{\prime}}$ & $d_{i i^{\prime}}$ & Pair & $\delta_{i{ }^{\prime}}$ & $d_{i i^{\prime}}$ & Pair & $\delta_{i{ }^{\prime}}$ & $d_{i{ }^{\prime \prime}}$ \\
\hline$(7,1)$ & 1 & 0.7419 & $(9,1)$ & 1 & 0.4838 & $(11,1)$ & 1 & 0.2332 \\
$(7,2)$ & 1 & 1 & $(9,2)$ & 1 & 0.4838 & $(11,2)$ & 0 & 0.2581 \\
$(7,3)$ & 0 & 0.5162 & $(9,3)$ & 1 & 0.7419 & $(11,3)$ & 0 & 0.5162 \\
$(7,4)$ & 1 & 0.7419 & $(9,4)$ & 1 & 0.4838 & $(11,4)$ & 1 & 0.2332 \\
$(7,5)$ & 1 & 1 & $(9,5)$ & 1 & 0.4838 & $(11,5)$ & 0 & 0.2581 \\
$(7,6)$ & 0 & 0.7668 & $(9,6)$ & 1 & 0.7419 & $(11,6)$ & 0 & 0.5162 \\
$(7,8)$ & 0 & 0.5162 & $(9,7)$ & 1 & 0.4838 & $(11,7)$ & 0 & 0 \\
$(7,9)$ & 0 & 0.5162 & $(9,8)$ & 1 & 0.4838 & $(11,8)$ & 0 & 0.2581 \\
$(7,10)$ & 1 & 0.7419 & $(9,10)$ & 1 & 0.4838 & $(11,9)$ & 0 & 0.5162 \\
$(7,11)$ & 1 & 1 & $(9,11)$ & 1 & 0.4838 & $(11,10)$ & 1 & 0.3585 \\
$(7,12)$ & 1 & 0.7668 & $(9,12)$ & 1 & 0.7419 & $(11,12)$ & 1 & 0.6415 \\
$(8,1)$ & 1 & 0.4838 & $(10,1)$ & 0 & 0.2581 & $(12,1)$ & 1 & 0.2332 \\
$(8,2)$ & 1 & 0.7419 & $(10,2)$ & 0 & 0.5162 & $(12,2)$ & 0.5 & 0.2332 \\
$(8,3)$ & 1 & 0.6415 & $(10,3)$ & 0 & 0.5162 & $(12,3)$ & 0 & 0.2581 \\
$(8,4)$ & 1 & 0.4838 & $(10,4)$ & 0 & 0.2581 & $(12,4)$ & 1 & 0.2332 \\
$(8,5)$ & 1 & 0.7419 & $(10,5)$ & 0 & 0.5162 & $(12,5)$ & 0 & 0.2332 \\
$(8,6)$ & 1 & 0.7668 & $(10,6)$ & 0 & 0.5162 & $(12,6)$ & 0 & 0.2581 \\
$(8,7)$ & 1 & 0.4838 & $(10,7)$ & 0 & 0.2581 & $(12,7)$ & 0 & 0.2332 \\
$(8,9)$ & 0 & 0.5162 & $(10,8)$ & 0 & 0.5162 & $(12,8)$ & 0 & 0 \\
$(8,10)$ & 1 & 0.4838 & $(10,9)$ & 0 & 0.5162 & $(12,9)$ & 0 & 0.2581 \\
$(8,11)$ & 1 & 0.7419 & $(10,11)$ & 0 & 0.6415 & $(12,10)$ & 1 & 0.3585 \\
$(8,12)$ & 1 & 1 & $(10,12)$ & 0 & 0.6415 & $(12,11)$ & 1 & 0.3585 \\
\hline & & & & & & & \\
\hline
\end{tabular}


Table 24. Overall dominance scores of each alternative pair of scenario of AGV fleet operation.

\begin{tabular}{|c|c|c|c|c|c|c|c|c|c|c|c|}
\hline Pair & $D_{i i^{\prime}}$ & Pair & $D_{i i^{\prime}}$ & Pair & $D_{i i^{\prime}}$ & Pair & $D_{i i^{\prime}}$ & Pair & $D_{i i^{\prime}}$ & Pair & $D_{i i^{\prime}}$ \\
\hline$(1,2)$ & 0.5364 & $(3,1)$ & 0.5685 & $(5,1)$ & 0.3590 & $(7,1)$ & 0.7843 & $(9,1)$ & 0.5685 & $(11,1)$ & 0.3590 \\
\hline$(1,3)$ & 0.4316 & $(3,2)$ & 0.5685 & $(5,2)$ & 0.5748 & $(7,2)$ & 1.0001 & $(9,2)$ & 0.5685 & $(11,2)$ & 0.2158 \\
\hline$(1,4)$ & 0.4253 & $(3,4)$ & 0.5685 & $(5,3)$ & 0.4316 & $(7,3)$ & 0.4316 & $(9,3)$ & 0.7843 & $(11,3)$ & 0.4316 \\
\hline$(1,5)$ & 0.6411 & $(3,5)$ & 0.5685 & $(5,4)$ & 0.5685 & $(7,4)$ & 0.7843 & $(9,4)$ & 0.5685 & $(11,4)$ & 0.3590 \\
\hline$(1,6)$ & 0.6411 & $(3,6)$ & 0.6203 & $(5,6)$ & 0.4316 & $(7,5)$ & 1.0001 & $(9,5)$ & 0.5685 & $(11,5)$ & 0.2158 \\
\hline$(1,7)$ & 0.2158 & $(3,7)$ & 0.5685 & $(5,7)$ & 0.0000 & $(7,6)$ & 0.6411 & $(9,6)$ & 0.7843 & $(11,6)$ & 0.4316 \\
\hline$(1,8)$ & 0.4316 & $(3,8)$ & 0.2998 & $(5,8)$ & 0.2158 & $(7,8)$ & 0.4316 & $(9,7)$ & 0.5685 & $(11,7)$ & 0.0000 \\
\hline$(1,9)$ & 0.4316 & $(3,9)$ & 0.2158 & $(5,9)$ & 0.4316 & $(7,9)$ & 0.4316 & $(9,8)$ & 0.5685 & $(11,8)$ & 0.2158 \\
\hline$(1,10)$ & 0.7843 & $(3,10)$ & 0.5685 & $(5,10)$ & 0.5685 & $(7,10)$ & 0.7843 & $(9,10)$ & 0.5685 & $(11,9)$ & 0.4316 \\
\hline$(1,11)$ & 0.6411 & $(3,11)$ & 0.5685 & $(5,11)$ & 0.7843 & $(7,11)$ & 1.0001 & $(9,11)$ & 0.5685 & $(11,10)$ & 0.4638 \\
\hline$(1,12)$ & 0.6411 & $(3,12)$ & 0.7843 & $(5,12)$ & 0.8051 & $(7,12)$ & 0.8051 & $(9,12)$ & 0.7843 & $(11,12)$ & 0.7004 \\
\hline$(2,1)$ & 0.4638 & $(4,1)$ & 0.5748 & $(6,1)$ & 0.3590 & $(6,1)$ & 0.5685 & $(10,1)$ & 0.2158 & $(12,1)$ & 0.3590 \\
\hline$(2,3)$ & 0.4316 & $(4,2)$ & 0.4316 & $(6,2)$ & 0.3590 & $(6,2)$ & 0.7843 & $(10,2)$ & 0.4316 & $(12,2)$ & 0.2770 \\
\hline$(2,4)$ & 0.5685 & $(4,3)$ & 0.4316 & $(6,3)$ & 0.3798 & $(6,3)$ & 0.7004 & $(10,3)$ & 0.4316 & $(12,3)$ & 0.2158 \\
\hline$(2,5)$ & 0.4253 & $(4,5)$ & 0.4316 & $(6,4)$ & 0.5685 & $(6,4)$ & 0.5685 & $(10,4)$ & 0.2158 & $(12,4)$ & 0.3590 \\
\hline$(2,6)$ & 0.6411 & $(4,6)$ & 0.4316 & $(6,5)$ & 0.5685 & $(6,5)$ & 0.7843 & $(10,5)$ & 0.4316 & $(12,5)$ & 0.1950 \\
\hline$(2,7)$ & 0.0000 & $(4,7)$ & 0.2158 & $(6,7)$ & 0.3590 & $(6,7)$ & 0.8051 & $(10,6)$ & 0.4316 & $(12,6)$ & 0.2158 \\
\hline$(2,8)$ & 0.2158 & $(4,8)$ & 0.4316 & $(6,8)$ & 0.1950 & $(6,8)$ & 0.5685 & $(10,7)$ & 0.2158 & $(12,7)$ & 0.1950 \\
\hline$(2,9)$ & 0.4316 & $(4,9)$ & 0.4316 & $(6,9)$ & 0.2158 & $(6,9)$ & 0.4316 & $(10,8)$ & 0.4316 & $(12,8)$ & 0.0000 \\
\hline$(2,10)$ & 0.5685 & $(4,10)$ & 0.7843 & $(6,10)$ & 0.5685 & $(6,10)$ & 0.5685 & $(10,9)$ & 0.4316 & $(12,9)$ & 0.2158 \\
\hline$(2,11)$ & 0.7843 & $(4,11)$ & 0.6411 & $(6,11)$ & 0.5685 & $(6,11)$ & 0.7843 & $(10,11)$ & 0.5364 & $(12,10)$ & 0.4638 \\
\hline$(2,12)$ & 0.7231 & $(4,12)$ & 0.6411 & $(6,12)$ & 0.7843 & $(6,12)$ & 1.0001 & $(10,12)$ & 0.5364 & $(12,11)$ & 0.4638 \\
\hline
\end{tabular}

Table 25. Appraisal score of each alternative pair.

\begin{tabular}{ccc}
\hline Scenarios & $S_{i}$ additive interval technique & Rank \\
\hline Scenario 1 & 0.0812 & 7 \\
Scenario 2 & 0.0869 & 4 \\
Scenario 3 & 0.0822 & 6 \\
Scenario 4 & 0.0731 & 8 \\
Scenario 5 & 0.0823 & 5 \\
Scenario 6 & 0.0554 & 9 \\
Scenario 7 & 0.1792 & 1 \\
Scenario 8 & 0.1710 & 2 \\
Scenario 9 & 0.1450 & 3 \\
Scenario 10 & 0.0487 & 11 \\
Scenario 11 & 0.0494 & 10 \\
Scenario 12 & 0.0357 & 12 \\
\hline
\end{tabular}

For the industry front layout selection is challenging and sometime tedious because of its inherent multiple objective nature and its data collection process proposed by Lin and Sharp [58,59]. Past experience and database can be used for the selection but this can not be justified by the objective values. Hence, sometime the evaluation may create conflict decision for the selection of best layout design. Facility layout design is a systematic strategic approach. The treatment of facilities planning requires highly sophisticated mathematical approach taking advantage of empirical and analytical approaches. The various industrial sectors like manufacturing organizations, mining, railroads etc. include the notion of continuous improvement in the layout design. It seems very reasonable to suggest some adequate and significant opportunity to improve planning process as practiced today by Tomkins et al. [60].

The literature for layout design problem falls into two categories; algorithmic and procedural approaches. Muther 
[61] gave procedural approaches to incorporate both qualitative and quantitative objectives in the design. AHP/ DEA is used in [62] for facilities layout design, [63] proposed TOPSIS and [64] proposed grey relational analysis in solving the problem of facility layout design selection and than [65] extended the same problem of facility layout selection by TOPSIS-DoE analysis.

In order to suggest some simple and feasible solution the problem of facility selection is analysed by combined EVAMIX method. In this example of the facility layout selection problem, 18 alternative layouts and 6 performance attributes are considered.

Table 26 shows the attribute values for 18 alternative plant layout, where flow distance and shape ratio and maintenance would be non-beneficial attributes, whereas adjacency scores, flexibility and accessibility are the beneficial attributes for ranking these alternative plant layouts.

Step I: Total 18 alternative along with their most applicable 6 attributes are tabulated and decision matrix is formed. This is carried out to clearly distinguish the beneficial and non-beneficial attributes, as well as to find the most influencing attribute to selection process.

Step II: The normalisation is carried out using (1) and
(2) for beneficial and non-beneficial attributes and given in Table 27.

Step III: The attributes considered in the example are all affecting the selection process to some extent but the maintenance planning involves the required space for engineers and tool movement.

Step IV: The dominance scores for each alternative pairs of layout designs are calculated and tabulated in Tables 28(a) and (b) using (5) and (6).

Step V: The standardized dominance is calculated based on the additive interval technique for all the pairs of alternative layout design using (7) and (8) for the ordinal and cardinal criteria respectively and given in Tables 29(a) and (b).

Step VI: The overall dominance score for each alternative pair $\left(i, i^{\prime}\right)$, is calculated using (9) which shows the degree by which layout design $i$ dominates the design $i^{\prime}$. These overall dominance score for all the pairs of alternative is shown in Tables 30(a) and (b).

Step VII: Finally the appraisal score for $i^{\text {th }}$ alternative pair $\left(S_{i}\right)$ is computed using (10). Higher the appraisal score better is layout design. The scores and ranking is given in Table 31 .

The scores and ranking is given in the performance

Table 26. Data table for facility layout selection [57].

\begin{tabular}{|c|c|c|c|c|c|c|}
\hline Layout & Adjacency & Flexibility & Accessibility & Shape ratio & Distance (m) & Maintenance \\
\hline Layout 1 & 8 & 0.0494 & 0.0294 & 8.280 & 185.95 & 0.0130 \\
\hline Layout 2 & 9 & 0.0494 & 0.0147 & 3.750 & 207.37 & 0.0519 \\
\hline Layout 3 & 8 & 0.0370 & 0.0147 & 7.850 & 206.38 & 0.0519 \\
\hline Layout 4 & 8 & 0.0370 & 0.0147 & 8.280 & 189.66 & 0.0519 \\
\hline Layout 5 & 8 & 0.0617 & 0.0147 & 7.710 & 211.46 & 0.0390 \\
\hline Layout 6 & 5 & 0.0494 & 0.0147 & 2.070 & 264.07 & 0.0519 \\
\hline Layout 7 & 8 & 0.0247 & 0.0735 & 14.000 & 228.00 & 0.0649 \\
\hline Layout 8 & 9 & 0.0370 & 0.0441 & 6.250 & 185.59 & 0.0390 \\
\hline Layout 9 & 9 & 0.0741 & 0.0441 & 7.850 & 185.85 & 0.0519 \\
\hline Layout 10 & 8 & 0.0741 & 0.0588 & 7.850 & 236.15 & 0.0649 \\
\hline Layout 11 & 8 & 0.0864 & 0.1029 & 2.000 & 183.18 & 0.0909 \\
\hline Layout 12 & 8 & 0.0370 & 0.0588 & 13.300 & 204.18 & 0.0260 \\
\hline Layout 13 & 8 & 0.0247 & 0.0735 & 8.140 & 225.26 & 0.0519 \\
\hline Layout 14 & 8 & 0.0247 & 0.0588 & 8.000 & 205.82 & 0.0519 \\
\hline Layout 15 & 9 & 0.0864 & 0.1176 & 8.280 & 170.14 & 0.1169 \\
\hline Layout 16 & 9 & 0.0741 & 0.0735 & 7.710 & 216.38 & 0.0519 \\
\hline Layout 17 & 8 & 0.0988 & 0.1324 & 10.300 & 179.80 & 0.0909 \\
\hline Layout 18 & 10 & 0.0741 & 0.0588 & 10.160 & 185.75 & 0.0390 \\
\hline
\end{tabular}


Table 27. Normalized data table for facility layout selection.

\begin{tabular}{ccccccc}
\hline Layout & Flexibility & Accessibility & Maintenance & Distance (m) & Adjacency & Shape ratio \\
\hline Layout 1 & 0.333333 & 0.1249 & 1 & 0.8317 & 0.6 & 0.4767 \\
Layout 2 & 0.333333 & 0.0000 & 0.625602 & 0.6036 & 0.8 & 0.8542 \\
Layout 3 & 0.165992 & 0.0000 & 0.625602 & 0.6142 & 0.6 & 0.5125 \\
Layout 4 & 0.165992 & 0.0000 & 0.625602 & 0.7922 & 0.6 & 0.4767 \\
Layout 5 & 0.499325 & 0.0000 & 0.749759 & 0.5601 & 0.6 & 0.5242 \\
Layout 6 & 0.333333 & 0.0000 & 0.625602 & 0.0000 & 0 & 0.9942 \\
Layout 7 & 0 & 0.4996 & 0.500481 & 0.3840 & 0.6 & 0.0000 \\
Layout 8 & 0.165992 & 0.2498 & 0.749759 & 0.8355 & 0.8 & 0.6458 \\
Layout 9 & 0.666667 & 0.2498 & 0.625602 & 0.8327 & 0.8 & 0.5125 \\
Layout 10 & 0.666667 & 0.3747 & 0.500481 & 0.2972 & 0.6 & 0.5125 \\
Layout 11 & 0.832659 & 0.7494 & 0.250241 & 0.8612 & 0.6 & 1.0000 \\
Layout 12 & 0.165992 & 0.3747 & 0.87488 & 0.6376 & 0.6 & 0.0583 \\
Layout 13 & 0 & 0.4996 & 0.625602 & 0.4132 & 0.6 & 0.4883 \\
Layout 14 & 0 & 0.3747 & 0.625602 & 0.6521 & 0.6 & 0.5000 \\
Layout 15 & 0.832659 & 0.8743 & 0 & 1.0000 & 0.8 & 0.4767 \\
Layout 16 & 0.666667 & 0.4996 & 0.625602 & 0.5077 & 0.8 & 0.5242 \\
Layout 17 & 1 & 1.0000 & 0.250241 & 0.8972 & 0.6 & 0.3083 \\
Layout 18 & 0.666667 & 0.3747 & 0.749759 & 0.8338 & 1 & 0.3200 \\
\hline
\end{tabular}

Table 28. (a) Dominance score of each alternative pair; (b) Dominance score of each alternative pair.

(a)

\begin{tabular}{|c|c|c|c|c|c|c|c|c|c|c|c|}
\hline Pair & $\alpha_{i i^{\prime}}$ & $\gamma_{i i^{\prime}}$ & Pair & $\alpha_{i i^{\prime}}$ & $\gamma_{i i^{\prime}}$ & Pair & $\alpha_{i i^{\prime}}$ & $\gamma_{i i^{\prime}}$ & Pair & $\alpha_{i i^{\prime}}$ & $\gamma_{i i^{\prime}}$ \\
\hline$(1,2)$ & 0.2917 & 0.8264 & $(3,1)$ & -0.4468 & 0 & $(5,1)$ & -0.1366 & 0.3471 & $(7,1)$ & -0.0128 & 0.4857 \\
\hline$(1,3)$ & 0.4468 & 1 & $(3,2)$ & -0.1551 & 0.3264 & $(5,2)$ & 0.2298 & 0.7572 & $(7,2)$ & -0.0128 & 0.4857 \\
\hline$(1,4)$ & 0.4468 & 1 & $(3,4)$ & 0 & 0.5000 & $(5,3)$ & 0.2298 & 0.7572 & $(7,3)$ & -0.0128 & 0.4857 \\
\hline$(1,5)$ & 0.1366 & 0.6529 & $(3,5)$ & -0.2298 & 0.2428 & $(5,4)$ & 0.2298 & 0.7572 & $(7,4)$ & -0.0128 & 0.4857 \\
\hline$(1,6)$ & 0.2917 & 0.8264 & $(3,6)$ & -0.1551 & 0.3264 & $(5,6)$ & 0.2298 & 0.7572 & $(7,5)$ & -0.0128 & 0.4857 \\
\hline$(1,7)$ & 0.0128 & 0.5143 & $(3,7)$ & 0.0128 & 0.5143 & $(5,7)$ & 0.0128 & 0.5143 & $(7,6)$ & -0.0128 & 0.4857 \\
\hline$(1,8)$ & 0.0128 & 0.5143 & $(3,8)$ & -0.2917 & 0.1736 & $(5,8)$ & -0.0619 & 0.4307 & $(7,8)$ & -0.0128 & 0.4857 \\
\hline$(1,9)$ & -0.2974 & 0.1672 & $(3,9)$ & -0.3721 & 0.0836 & $(5,9)$ & -0.2974 & 0.1672 & $(7,9)$ & -0.0128 & 0.4857 \\
\hline$(1,10)$ & -0.2974 & 0.1672 & $(3,10)$ & -0.2974 & 0.1672 & $(5,10)$ & -0.2974 & 0.1672 & $(7,10)$ & 0.0619 & 0.5693 \\
\hline$(1,11)$ & -0.2974 & 0.1672 & $(3,11)$ & -0.2974 & 0.1672 & $(5,11)$ & -0.2974 & 0.1672 & $(7,11)$ & -0.2974 & 0.1672 \\
\hline$(1,12)$ & 0.0128 & 0.5143 & $(3,12)$ & -0.2917 & 0.1736 & $(5,12)$ & -0.1366 & 0.3471 & $(7,12)$ & -0.0128 & 0.4857 \\
\hline$(1,13)$ & 0.0128 & 0.5143 & $(3,13)$ & -0.0619 & 0.4307 & $(5,13)$ & 0.0128 & 0.5143 & $(7,13)$ & -0.0747 & 0.4164 \\
\hline$(1,14)$ & 0.0128 & 0.5143 & $(3,14)$ & -0.0619 & 0.4307 & $(5,14)$ & 0.0128 & 0.5143 & $(7,14)$ & 0.1423 & 0.6592 \\
\hline$(1,15)$ & -0.2974 & 0.1672 & $(3,15)$ & -0.2974 & 0.1672 & $(5,15)$ & -0.2974 & 0.1672 & $(7,15)$ & -0.2974 & 0.1672 \\
\hline$(1,16)$ & -0.2974 & 0.1672 & $(3,16)$ & -0.3721 & 0.0836 & $(5,16)$ & -0.2974 & 0.1672 & $(7,16)$ & -0.2298 & 0.2428 \\
\hline$(1,17)$ & -0.2974 & 0.1672 & $(3,17)$ & -0.2974 & 0.1672 & $(5,17)$ & -0.2974 & 0.1672 & $(7,17)$ & -0.2974 & 0.1672 \\
\hline$(1,18)$ & -0.2974 & 0.1672 & $(3,18)$ & -0.4468 & 0 & $(5,18)$ & -0.3721 & 0.0836 & $(7,18)$ & -0.0128 & 0.4857 \\
\hline$(2,1)$ & -0.2917 & 0.1736 & $(4,1)$ & -0.4468 & 0 & $(6,1)$ & -0.2917 & 0.1736 & $(8,1)$ & -0.0128 & 0.4857 \\
\hline$(2,3)$ & 0.1551 & 0.6736 & $(4,2)$ & -0.1551 & 0.3264 & $(6,2)$ & 0 & 0.5000 & $(8,2)$ & 0.1366 & 0.6529 \\
\hline$(2,4)$ & 0.1551 & 0.6736 & $(4,3)$ & 0 & 0.5000 & $(6,3)$ & 0.1551 & 0.6736 & $(8,3)$ & 0.2917 & 0.8264 \\
\hline$(2,5)$ & -0.2298 & 0.2428 & $(4,5)$ & -0.2298 & 0.2428 & $(6,4)$ & 0.1551 & 0.6736 & $(8,4)$ & 0.2917 & 0.8264 \\
\hline$(2,6)$ & 0 & 0.5000 & $(4,6)$ & -0.1551 & 0.3264 & $(6,5)$ & -0.2298 & 0.2428 & $(8,5)$ & 0.0619 & 0.5698 \\
\hline$(2,7)$ & 0.0128 & 0.5143 & $(4,7)$ & 0.0128 & 0.5143 & $(6,7)$ & 0.0128 & 0.5143 & $(8,7)$ & 0.1366 & 0.6529 \\
\hline$(2,8)$ & -0.1366 & 0.3471 & $(4,8)$ & -0.2917 & 0.1736 & $(6,8)$ & -0.1366 & 0.3471 & $(8,8)$ & 0.0128 & 0.5143 \\
\hline$(2,9)$ & -0.3721 & 0.0836 & $(4,9)$ & -0.3721 & 0.0836 & $(6,9)$ & -0.3721 & 0.0836 & $(8,9)$ & -0.0804 & 0.4100 \\
\hline$(2,10)$ & -0.2974 & 0.1672 & $(4,10)$ & -0.2974 & 0.1672 & $(6,10)$ & -0.2974 & 0.1672 & $(8,10)$ & -0.2974 & 0.1672 \\
\hline$(2,11)$ & -0.2974 & 0.1672 & $(4,11)$ & -0.2974 & 0.1672 & $(6,11)$ & -0.2974 & 0.1672 & $(8,11)$ & -0.2974 & 0.1672 \\
\hline$(2,12)$ & -0.1366 & 0.3471 & $(4,12)$ & -0.2917 & 0.1736 & $(6,12)$ & -0.1366 & 0.3471 & $(8,12)$ & -0.2917 & 0.1736 \\
\hline$(2,13)$ & -0.0619 & 0.4307 & $(4,13)$ & -0.0619 & 0.4307 & $(6,13)$ & -0.0619 & 0.4307 & $(8,13)$ & 0.0128 & 0.5143 \\
\hline$(2,14)$ & -0.0619 & 0.4307 & $(4,14)$ & -0.0619 & 0.4307 & $(6,14)$ & -0.0619 & 0.4307 & $(8,14)$ & 0.0128 & 0.5143 \\
\hline$(2,15)$ & -0.2974 & 0.1672 & $(4,15)$ & -0.2974 & 0.1672 & $(6,15)$ & -0.2974 & 0.1672 & $(8,15)$ & -0.2974 & 0.1672 \\
\hline$(2,16)$ & -0.3721 & 0.0836 & $(4,16)$ & -0.3721 & 0.0836 & $(6,16)$ & -0.3721 & 0.0836 & $(8,16)$ & -0.2974 & 0.1672 \\
\hline$(2,17)$ & -0.2974 & 0.1672 & $(4,17)$ & -0.2974 & 0.1672 & $(6,17)$ & -0.2974 & 0.1672 & $(8,17)$ & -0.2974 & 0.1672 \\
\hline$(2,18)$ & -0.4468 & 0 & $(4,18)$ & -0.4468 & 0 & $(6,18)$ & -0.4468 & 0 & $(8,18)$ & -0.3721 & 0.0836 \\
\hline
\end{tabular}


(b)

\begin{tabular}{|c|c|c|c|c|c|c|c|c|c|c|c|}
\hline Pair & $\alpha_{i i^{\prime}}$ & $\gamma_{i{ }^{\prime}}$ & Pair & $\alpha_{i i^{\prime}}$ & $\gamma_{i i^{\prime}}$ & Pair & $\alpha_{i i^{\prime}}$ & $\gamma_{i i^{\prime}}$ & Pair & $\alpha_{i i^{\prime}}$ & $\gamma_{i i^{\prime}}$ \\
\hline$(9,1)$ & 0.2974 & 0.8328 & $(11,1)$ & 0.2974 & 0.8328 & $(13,1)$ & -0.0128 & 0.4857 & $(15,1)$ & 0.2974 & 0.8328 \\
\hline$(9,2)$ & 0.3721 & 0.9164 & $(11,2)$ & 0.2974 & 0.8328 & $(13,2)$ & 0.0619 & 0.5693 & $(15,2)$ & 0.2974 & 0.8328 \\
\hline$(9,3)$ & 0.3721 & 0.9164 & $(11,3)$ & 0.2974 & 0.8328 & $(13,3)$ & 0.0619 & 0.5693 & $(15,3)$ & 0.2974 & 0.8328 \\
\hline$(9,4)$ & 0.3721 & 0.9164 & $(11,4)$ & 0.2974 & 0.8328 & $(13,4)$ & 0.0619 & 0.5693 & $(15,4)$ & 0.2974 & 0.8328 \\
\hline$(9,5)$ & 0.2974 & 0.8328 & $(11,5)$ & 0.2974 & 0.8328 & $(13,5)$ & -0.0128 & 0.4857 & $(15,5)$ & 0.2974 & 0.8328 \\
\hline$(9,6)$ & 0.3721 & 0.9164 & $(11,6)$ & 0.2974 & 0.8328 & $(13,6)$ & 0.0619 & 0.5693 & $(15,6)$ & 0.2974 & 0.8328 \\
\hline$(9,7)$ & 0.0804 & 0.5900 & $(11,7)$ & 0.2974 & 0.8328 & $(13,7)$ & 0.0747 & 0.5836 & $(15,7)$ & 0.2974 & 0.8328 \\
\hline$(9,8)$ & -0.1423 & 0.3408 & $(11,8)$ & 0.2974 & 0.8328 & $(13,8)$ & -0.0128 & 0.4857 & $(15,8)$ & 0.2974 & 0.8328 \\
\hline$(9,10)$ & -0.1423 & 0.3408 & $(11,9)$ & 0.2974 & 0.8328 & $(13,9)$ & 0.0619 & 0.5693 & $(15,9)$ & 0.2974 & 0.8328 \\
\hline$(9,11)$ & -0.2974 & 0.1672 & $(11,10)$ & 0.2974 & 0.8328 & $(13,10)$ & 0.1366 & 0.6529 & $(15,10)$ & 0.2974 & 0.8328 \\
\hline$(9,12)$ & -0.1366 & 0.3471 & $(11,12)$ & 0.2974 & 0.8328 & $(13,11)$ & -0.2974 & 0.1672 & $(15,11)$ & 0.1423 & 0.6592 \\
\hline$(9,13)$ & -0.0619 & 0.4307 & $(11,13)$ & 0.2974 & 0.8328 & $(13,12)$ & -0.0128 & 0.4857 & $(15,12)$ & 0.2974 & 0.8328 \\
\hline$(9,14)$ & -0.0619 & 0.4307 & $(11,14)$ & 0.2974 & 0.8328 & $(13,14)$ & 0.217 & 0.7428 & $(15,13)$ & 0.2974 & 0.8328 \\
\hline$(9,15)$ & -0.2974 & 0.1672 & $(11,15)$ & -0.1423 & 0.3408 & $(13,15)$ & -0.2974 & 0.1672 & $(15,14)$ & 0.2974 & 0.8328 \\
\hline$(9,16)$ & -0.217 & 0.2572 & $(11,16)$ & 0.2974 & 0.8328 & $(13,16)$ & -0.1551 & 0.3264 & $(15,16)$ & 0.2974 & 0.8328 \\
\hline$(9,17)$ & -0.2974 & 0.1672 & $(11,17)$ & -0.3721 & 0.0836 & $(13,17)$ & -0.2974 & 0.1672 & $(15,17)$ & -0.4468 & 0.0000 \\
\hline$(9,18)$ & -0.2917 & 0.1736 & $(11,18)$ & 0.2974 & 0.8328 & $(13,18)$ & -0.0128 & 0.4857 & $(15,18)$ & 0.2974 & 0.8328 \\
\hline$(10,1)$ & 0.2974 & 0.8328 & $(12,1)$ & -0.0128 & 0.4857 & $(14,1)$ & -0.0128 & 0.4857 & $(16,1)$ & 0.2974 & 0.8328 \\
\hline$(10,2)$ & 0.2974 & 0.8328 & $(12,2)$ & 0.1366 & 0.6529 & $(14,2)$ & 0.0619 & 0.5693 & $(16,2)$ & 0.3721 & 0.9164 \\
\hline$(10,3)$ & 0.2974 & 0.8328 & $(12,3)$ & 0.2917 & 0.8264 & $(14,3)$ & 0.0619 & 0.5693 & $(16,3)$ & 0.3721 & 0.9164 \\
\hline$(10,4)$ & 0.2974 & 0.8328 & $(12,4)$ & 0.2917 & 0.8264 & $(14,4)$ & 0.0619 & 0.5693 & $(16,4)$ & 0.3721 & 0.9164 \\
\hline$(10,5)$ & 0.2974 & 0.8328 & $(12,5)$ & 0.1366 & 0.6529 & $(14,5)$ & -0.0128 & 0.4857 & $(16,5)$ & 0.2974 & 0.8328 \\
\hline$(10,6)$ & 0.2974 & 0.8328 & $(12,6)$ & 0.1366 & 0.6529 & $(14,6)$ & 0.0619 & 0.5693 & $(16,6)$ & 0.3721 & 0.9164 \\
\hline$(10,7)$ & -0.0619 & 0.4307 & $(12,7)$ & 0.0128 & 0.5143 & $(14,7)$ & -0.1423 & 0.3408 & $(16,7)$ & 0.2298 & 0.7572 \\
\hline$(10,8)$ & 0.2974 & 0.8328 & $(12,8)$ & 0.2917 & 0.8264 & $(14,8)$ & -0.0128 & 0.4857 & $(16,8)$ & 0.2974 & 0.8328 \\
\hline$(10,9)$ & 0.1423 & 0.6592 & $(12,9)$ & 0.1366 & 0.6529 & $(14,9)$ & 0.0619 & 0.5693 & $(16,9)$ & 0.217 & 0.7428 \\
\hline$(10,11)$ & -0.2974 & 0.1672 & $(12,10)$ & -0.0804 & 0.4100 & $(14,10)$ & -0.0804 & 0.4100 & $(16,10)$ & 0.2917 & 0.8264 \\
\hline$(10,12)$ & 0.0804 & 0.5900 & $(12,11)$ & -0.2974 & 0.1672 & $(14,11)$ & -0.2974 & 0.1672 & $(16,11)$ & -0.2974 & 0.1672 \\
\hline$(10,13)$ & -0.1366 & 0.3471 & $(12,13)$ & 0.0128 & 0.5143 & $(14,12)$ & -0.2298 & 0.2428 & $(16,12)$ & 0.2974 & 0.8328 \\
\hline$(10,14)$ & 0.0804 & 0.5900 & $(12,14)$ & 0.2298 & 0.7572 & $(14,13)$ & -0.217 & 0.2572 & $(16,13)$ & 0.1551 & 0.6736 \\
\hline$(10,15)$ & -0.2974 & 0.1672 & $(12,15)$ & -0.2974 & 0.1672 & $(14,15)$ & -0.2974 & 0.1672 & $(16,14)$ & 0.3721 & 0.9164 \\
\hline$(10,16)$ & -0.2917 & 0.1736 & $(12,16)$ & -0.2974 & 0.1672 & $(14,16)$ & -0.3721 & 0.0836 & $(16,15)$ & -0.2974 & 0.1672 \\
\hline$(10,17)$ & -0.2974 & 0.1672 & $(12,17)$ & -0.2974 & 0.1672 & $(14,17)$ & -0.2974 & 0.1672 & $(16,17)$ & -0.2974 & 0.1672 \\
\hline$(10,18)$ & -0.0747 & 0.4164 & $(12,18)$ & -0.0804 & 0.4100 & $(14,18)$ & -0.2298 & 0.2428 & $(16,18)$ & 0.1423 & 0.6592 \\
\hline
\end{tabular}


Table 29. (a) Standardised dominance score of each alternative pair; (b) Standardised dominance score of each alternative pair.

(a)

\begin{tabular}{|c|c|c|c|c|c|c|c|c|c|c|c|}
\hline Pair & $\delta_{i i^{\prime}}$ & $d_{i i^{\prime}}$ & Pair & $\delta_{i i^{\prime}}$ & $d_{i i^{\prime}}$ & Pair & $\delta_{i i^{\prime}}$ & $d_{i i^{\prime}}$ & Pair & $\delta_{i i^{\prime}}$ & $d_{i i^{\prime}}$ \\
\hline$(1,2)$ & -0.2121 & 0.3083 & $(3,1)$ & -0.1705 & 0.3459 & $(5,1)$ & -0.1705 & 0.3459 & $(7,1)$ & 0.0109 & 0.5099 \\
\hline$(1,3)$ & 0.1705 & 0.6541 & $(3,2)$ & -0.2121 & 0.3083 & $(5,2)$ & -0.3717 & 0.1640 & $(7,2)$ & -0.3717 & 0.1640 \\
\hline$(1,4)$ & 0.0798 & 0.5721 & $(3,4)$ & -0.1705 & 0.3459 & $(5,3)$ & -0.1705 & 0.3459 & $(7,3)$ & 0.0109 & 0.5099 \\
\hline$(1,5)$ & 0.1705 & 0.6541 & $(3,5)$ & 0.1705 & 0.6541 & $(5,4)$ & -0.1705 & 0.3459 & $(7,4)$ & 0.0109 & 0.5099 \\
\hline$(1,6)$ & 0.5531 & 1 & $(3,6)$ & 0.5531 & 1 & $(5,6)$ & 0.5531 & 1 & $(7,5)$ & 0.0109 & 0.5099 \\
\hline$(1,7)$ & -0.0109 & 0.4901 & $(3,7)$ & -0.0109 & 0.4901 & $(5,7)$ & -0.0109 & 0.4901 & $(7,6)$ & 0.5531 & 1 \\
\hline$(1,8)$ & -0.3717 & 0.1640 & $(3,8)$ & -0.3717 & 0.1640 & $(5,8)$ & -0.3717 & 0.1640 & $(7,8)$ & -0.3717 & 0.1640 \\
\hline$(1,9)$ & -0.3717 & 0.1640 & $(3,9)$ & -0.4624 & 0.0820 & $(5,9)$ & -0.5531 & 0 & $(7,9)$ & -0.3717 & 0.1640 \\
\hline$(1,10)$ & 0.1705 & 0.6541 & $(3,10)$ & 0.0798 & 0.5721 & $(5,10)$ & -0.0109 & 0.4901 & $(7,10)$ & 0.1705 & 0.6541 \\
\hline$(1,11)$ & 0.0109 & 0.5099 & $(3,11)$ & 0.0109 & 0.5099 & $(5,11)$ & 0.0109 & 0.5099 & $(7,11)$ & 0.0109 & 0.5099 \\
\hline$(1,12)$ & -0.0109 & 0.4901 & $(3,12)$ & -0.1705 & 0.3459 & $(5,12)$ & -0.1705 & 0.3459 & $(7,12)$ & 0.0109 & 0.5099 \\
\hline$(1,13)$ & 0.1705 & 0.6541 & $(3,13)$ & -0.0109 & 0.4901 & $(5,13)$ & -0.0109 & 0.4901 & $(7,13)$ & 0.0109 & 0.5099 \\
\hline$(1,14)$ & 0.1705 & 0.6541 & $(3,14)$ & -0.1705 & 0.3459 & $(5,14)$ & -0.1705 & 0.3459 & $(7,14)$ & 0.0109 & 0.5099 \\
\hline$(1,15)$ & -0.4624 & 0.0820 & $(3,15)$ & -0.5531 & 0 & $(5,15)$ & -0.5531 & 0.0000 & $(7,15)$ & -0.3717 & 0.1640 \\
\hline$(1,16)$ & -0.2121 & 0.3083 & $(3,16)$ & -0.2121 & 0.3083 & $(5,16)$ & -0.3028 & 0.2263 & $(7,16)$ & -0.3717 & 0.1640 \\
\hline$(1,17)$ & -0.1705 & 0.3459 & $(3,17)$ & -0.1705 & 0.3459 & $(5,17)$ & -0.1705 & 0.3459 & $(7,17)$ & 0.0109 & 0.5099 \\
\hline$(1,18)$ & -0.5531 & 0.0000 & $(3,18)$ & -0.5531 & 0 & $(5,18)$ & -0.5531 & 0 & $(7,18)$ & -0.3717 & 0.1640 \\
\hline$(2,1)$ & 0.2121 & 0.6917 & $(4,1)$ & -0.0798 & 0.4279 & $(6,1)$ & -0.5531 & 0 & $(8,1)$ & 0.3717 & 0.8360 \\
\hline$(2,3)$ & 0.2121 & 0.6917 & $(4,2)$ & -0.2121 & 0.3083 & $(6,2)$ & -0.5531 & 0 & $(8,2)$ & 0.1705 & 0.6541 \\
\hline$(2,4)$ & 0.2121 & 0.6917 & $(4,3)$ & 0.1705 & 0.6541 & $(6,3)$ & -0.5531 & 0 & $(8,3)$ & 0.3717 & 0.8360 \\
\hline$(2,5)$ & 0.3717 & 0.8360 & $(4,5)$ & 0.1705 & 0.6541 & $(6,4)$ & -0.5531 & 0 & $(8,4)$ & 0.3717 & 0.8360 \\
\hline$(2,6)$ & 0.5531 & 1 & $(4,6)$ & 0.5531 & 1 & $(6,5)$ & -0.5531 & 0 & $(8,5)$ & 0.3717 & 0.8360 \\
\hline$(2,7)$ & 0.3717 & 0.8360 & $(4,7)$ & -0.0109 & 0.4901 & $(6,7)$ & -0.5531 & 0 & $(8,7)$ & 0.5531 & 1 \\
\hline$(2,8)$ & -0.1705 & 0.3459 & $(4,8)$ & -0.3717 & 0.1640 & $(6,8)$ & -0.5531 & 0 & $(8,8)$ & 0.3717 & 0.8360 \\
\hline$(2,9)$ & -0.1705 & 0.3459 & $(4,9)$ & -0.3717 & 0.1640 & $(6,9)$ & -0.5531 & 0 & $(8,9)$ & -0.0109 & 0.4901 \\
\hline$(2,10)$ & 0.3717 & 0.8360 & $(4,10)$ & 0.1705 & 0.6541 & $(6,10)$ & -0.5531 & 0 & $(8,10)$ & 0.3717 & 0.8360 \\
\hline$(2,11)$ & 0.3935 & 0.8557 & $(4,11)$ & 0.0109 & 0.5099 & $(6,11)$ & -0.3717 & 0.1640 & $(8,11)$ & 0.3935 & 0.8557 \\
\hline$(2,12)$ & 0.2121 & 0.6917 & $(4,12)$ & -0.0109 & 0.4901 & $(6,12)$ & -0.5531 & 0 & $(8,12)$ & 0.3717 & 0.8360 \\
\hline$(2,13)$ & 0.3717 & 0.8360 & $(4,13)$ & 0.1705 & 0.6541 & $(6,13)$ & -0.5531 & 0 & $(8,13)$ & 0.3717 & 0.8360 \\
\hline$(2,14)$ & 0.2121 & 0.6917 & $(4,14)$ & 0.1705 & 0.6541 & $(6,14)$ & -0.5531 & 0 & $(8,14)$ & 0.3717 & 0.8360 \\
\hline$(2,15)$ & -0.1705 & 0.3459 & $(4,15)$ & -0.4624 & 0.0820 & $(6,15)$ & -0.5531 & 0 & $(8,15)$ & -0.1705 & 0.3459 \\
\hline$(2,16)$ & -0.0109 & 0.4901 & $(4,16)$ & -0.2121 & 0.3083 & $(6,16)$ & -0.5531 & 0 & $(8,16)$ & -0.0109 & 0.4901 \\
\hline$(2,17)$ & 0.2121 & 0.6917 & $(4,17)$ & -0.1705 & 0.3459 & $(6,17)$ & -0.5531 & 0 & $(8,17)$ & 0.2121 & 0.6917 \\
\hline$(2,18)$ & -0.5531 & 0 & $(4,18)$ & -0.5531 & 0 & $(6,18)$ & -0.5531 & 0 & $(8,18)$ & -0.3935 & 0.1443 \\
\hline
\end{tabular}


(b)

\begin{tabular}{|c|c|c|c|c|c|c|c|c|c|c|c|c|c|c|}
\hline Pair & $\delta_{i i^{\prime}}$ & $d_{i i^{\prime}}$ & Pair & $\delta_{i^{\prime}}$ & $d_{i i^{\prime}}$ & Pair & $\delta_{i i^{\prime}}$ & $d_{i i^{\prime}}$ & Pair & $\delta_{i i^{\prime}}$ & $d_{i i^{\prime}}$ & Pair & $\delta_{i i^{\prime}}$ & $d_{i i^{\prime}}$ \\
\hline$(9,1)$ & 0.3717 & 0.8360 & $(11,1)$ & -0.0109 & 0.4901 & $(13,1)$ & -0.1705 & 0.3459 & $(15,1)$ & 0.4624 & 0.9180 & $(17,1)$ & 0.1705 & 0.6541 \\
\hline$(9,2)$ & 0.1705 & 0.6541 & $(11,2)$ & -0.3935 & 0.1443 & $(13,2)$ & -0.3717 & 0.1640 & $(15,2)$ & 0.1705 & 0.6541 & $(17,2)$ & -0.2121 & 0.3083 \\
\hline$(9,3)$ & 0.4624 & 0.9180 & $(11,3)$ & -0.0109 & 0.4901 & $(13,3)$ & 0.0109 & 0.5099 & $(15,13)$ & 0.5531 & 1 & $(17,3)$ & 0.1705 & 0.6541 \\
\hline$(9,4)$ & 0.3717 & 0.8360 & $(11,4)$ & -0.0109 & 0.4901 & $(13,4)$ & -0.1705 & 0.3459 & $(15,4)$ & 0.4624 & 0.9180 & $(17,4)$ & 0.1705 & 0.6541 \\
\hline$(9,5)$ & 0.5531 & 1 & $(11,5)$ & -0.0109 & 0.4901 & $(13,5)$ & 0.0109 & 0.5099 & $(15,5)$ & 0.5531 & 1 & $(17,5)$ & 0.1705 & 0.6541 \\
\hline$(9,6)$ & 0.5531 & 1 & $(11,6)$ & 0.3717 & 0.8360 & $(13,6)$ & 0.5531 & 1 & $(15,6)$ & 0.5531 & 1 & $(17,6)$ & 0.5531 & 1 \\
\hline$(9,7)$ & 0.0109 & 0.5099 & $(11,7)$ & -0.0109 & 0.4901 & $(13,7)$ & -0.0109 & 0.4901 & $(15,7)$ & 0.3717 & 0.8360 & $(17,7)$ & -0.0109 & 0.4901 \\
\hline$(9,8)$ & 0.4624 & 0.9180 & $(11,8)$ & -0.3935 & 0.1443 & $(13,8)$ & -0.3717 & 0.1640 & $(15,8)$ & 0.1705 & 0.6541 & $(17,8)$ & -0.2121 & 0.3083 \\
\hline$(9,10)$ & 0.4624 & 0.9180 & $(11,9)$ & -0.3935 & 0.1443 & $(13,9)$ & -0.3717 & 0.1640 & $(15,9)$ & 0.1705 & 0.6541 & $(17,9)$ & -0.2121 & 0.3083 \\
\hline$(9,11)$ & 0.3935 & 0.8557 & $(11,10)$ & -0.0109 & 0.4901 & $(13,10)$ & 0.1705 & 0.6541 & $(15,10)$ & 0.5531 & 1 & $(17,10)$ & 0.1705 & 0.6541 \\
\hline$(9,12)$ & 0.3717 & 0.8360 & $(11,12)$ & -0.0109 & 0.4901 & $(13,11)$ & 0.0109 & 0.5099 & $(15,11)$ & 0.5531 & 1 & $(17,11)$ & 0.1705 & 0.6541 \\
\hline$(9,13)$ & 0.3717 & 0.8360 & $(11,13)$ & -0.0109 & 0.4901 & $(13,12)$ & -0.1705 & 0.3459 & $(15,12)$ & 0.3717 & 0.8360 & $(17,12)$ & -0.0109 & 0.4901 \\
\hline$(9,14)$ & 0.3717 & 0.8360 & $(11,14)$ & -0.0109 & 0.4901 & $(13,14)$ & 0.0109 & 0.5099 & $(15,13)$ & 0.5531 & 1 & $(17,13)$ & 0.1705 & 0.6541 \\
\hline$(9,15)$ & -0.1705 & 0.3459 & $(11,15)$ & -0.5531 & 0 & $(13,15)$ & -0.5531 & 0 & $(15,14)$ & 0.5531 & 1 & $(17,14)$ & 0.1705 & 0.6541 \\
\hline$(9,16)$ & 0.1705 & 0.6541 & $(11,16)$ & -0.3935 & 0.1443 & $(13,16)$ & -0.3717 & 0.1640 & $(15,16)$ & 0.1705 & 0.6541 & $(17,15)$ & -0.3717 & 0.1640 \\
\hline$(9,17)$ & 0.2121 & 0.6917 & $(11,17)$ & -0.1705 & 0.3459 & $(13,17)$ & -0.1705 & 0.3459 & $(15,17)$ & 0.3717 & 0.8360 & $(17,16)$ & -0.2121 & 0.3083 \\
\hline$(9,18)$ & -0.5531 & 0 & $(11,18)$ & -0.3935 & 0.1443 & $(13,18)$ & -0.5531 & 0 & $(15,18)$ & -0.3935 & 0.1443 & $(17,18)$ & -0.2121 & 0.3083 \\
\hline$(10,1)$ & -0.1705 & 0.3459 & $(12,1)$ & 0.0109 & 0.5099 & $(14,1)$ & -0.1705 & 0.3459 & $(16,1)$ & 0.2121 & 0.6917 & $(18,1)$ & 0.5531 & 1 \\
\hline$(10,2)$ & -0.3717 & 0.1640 & $(12,2)$ & -0.2121 & 0.3083 & $(14,2)$ & -0.2121 & 0.3083 & $(16,2)$ & 0.0109 & 0.5099 & $(18,2)$ & 0.5531 & 1 \\
\hline$(10,3)$ & -0.0798 & 0.4279 & $(12,3)$ & 0.1705 & 0.6541 & $(14,3)$ & 0.1705 & 0.6541 & $(16,3)$ & 0.2121 & 0.6917 & $(18,3)$ & 0.5531 & 1 \\
\hline$(10,4)$ & -0.1705 & 0.3459 & $(12,4)$ & 0.0109 & 0.5099 & $(14,4)$ & -0.1705 & 0.3459 & $(16,4)$ & 0.2121 & 0.6917 & $(18,4)$ & 0.5531 & 1 \\
\hline$(10,5)$ & 0.0109 & 0.5099 & $(12,5)$ & 0.1705 & 0.6541 & $(14,5)$ & 0.1705 & 0.6541 & $(16,5)$ & 0.3028 & 0.7737 & $(18,5)$ & 0.5531 & 1 \\
\hline$(10,6)$ & 0.5531 & 1 & $(12,6)$ & 0.5531 & 1 & $(14,6)$ & 0.5531 & 1 & $(16,6)$ & 0.5531 & 1 & $(18,6)$ & 0.5531 & 1 \\
\hline$(10,7)$ & -0.1705 & 0.3459 & $(12,7)$ & -0.0109 & 0.4901 & $(14,7)$ & -0.0109 & 0.4901 & $(16,7)$ & 0.3717 & 0.8360 & $(18,7)$ & 0.3717 & 0.8360 \\
\hline$(10,8)$ & -0.3717 & 0.1640 & $(12,8)$ & -0.3717 & 0.1640 & $(14,8)$ & -0.3717 & 0.1640 & $(16,8)$ & 0.0109 & 0.5099 & $(18,8)$ & 0.3935 & 0.8557 \\
\hline$(10,9)$ & -0.4624 & 0.0820 & $(12,9)$ & -0.3717 & 0.1640 & $(14,9)$ & -0.3717 & 0.1640 & $(16,9)$ & -0.1705 & 0.3459 & $(18,9)$ & 0.5531 & 1 \\
\hline$(10,11)$ & 0.0109 & 0.5099 & $(12,10)$ & 0.1705 & 0.6541 & $(14,10)$ & 0.1705 & 0.6541 & $(16,10)$ & 0.3717 & 0.8360 & $(18,10)$ & 0.5531 & 1 \\
\hline$(10,12)$ & -0.1705 & 0.3459 & $(12,11)$ & 0.0109 & 0.5099 & $(14,11)$ & 0.0109 & 0.5099 & $(16,11)$ & 0.3935 & 0.8557 & $(18,11)$ & 0.3935 & 0.8557 \\
\hline$(10,13)$ & -0.1705 & 0.3459 & $(12,13)$ & 0.1705 & 0.6541 & $(14,12)$ & -0.0109 & 0.4901 & $(16,12)$ & 0.2121 & 0.6917 & $(18,12)$ & 0.3717 & 0.8360 \\
\hline$(10,14)$ & -0.1705 & 0.3459 & $(12,14)$ & 0.0109 & 0.5099 & $(14,13)$ & -0.0109 & 0.4901 & $(16,13)$ & 0.3717 & 0.8360 & $(18,13)$ & 0.5531 & 1 \\
\hline$(10,15)$ & -0.5531 & 0 & $(12,15)$ & -0.3717 & 0.1640 & $(14,15)$ & -0.5531 & 0 & $(16,14)$ & 0.2121 & 0.6917 & $(18,14)$ & 0.5531 & 1 \\
\hline$(10,16)$ & -0.3717 & 0.1640 & $(12,16)$ & -0.2121 & 0.3083 & $(14,16)$ & -0.2121 & 0.3083 & $(16,15)$ & -0.1705 & 0.3459 & $(18,15)$ & 0.3935 & 0.8557 \\
\hline$(10,17)$ & -0.1705 & 0.3459 & $(12,17)$ & 0.0109 & 0.5099 & $(14,17)$ & -0.1705 & 0.3459 & $(16,17)$ & 0.2121 & 0.6917 & $(18,16)$ & 0.5531 & 1 \\
\hline$(10,18)$ & -0.5531 & 0 & $(12,18)$ & -0.3717 & 0.1640 & $(14,18)$ & -0.5531 & 0 & $(16,18)$ & -0.5531 & 0 & $(18,17)$ & 0.2121 & 0.6917 \\
\hline
\end{tabular}


Table 30. (a) Overall dominance score of each alternative pair; (b) Overall dominance score of each pair.

(a)

\begin{tabular}{|c|c|c|c|c|c|c|c|c|c|c|c|}
\hline Pair & $D_{i i^{\prime}}$ & Pair & $D_{i i^{\prime}}$ & Pair & $D_{i i^{\prime}}$ & Pair & $D_{i i^{\prime}}$ & Pair & $D_{i i^{\prime}}$ & Pair & $D_{i i^{\prime}}$ \\
\hline$(1,2)$ & 0.5398 & $(3,1)$ & 0.1913 & $(5,1)$ & 0.3464 & $(7,1)$ & 0.4990 & $(9,1)$ & 0.8345 & $(11,1)$ & 0.6432 \\
\hline$(1,3)$ & 0.8086 & $(3,2)$ & 0.3164 & $(5,2)$ & 0.4290 & $(7,2)$ & 0.3077 & $(9,2)$ & 0.7713 & $(11,2)$ & 0.4519 \\
\hline$(1,4)$ & 0.7633 & $(3,4)$ & 0.4147 & $(5,3)$ & 0.5296 & $(7,3)$ & 0.4990 & $(9,3)$ & 0.9172 & $(11,3)$ & 0.6432 \\
\hline$(1,5)$ & 0.6535 & $(3,5)$ & 0.4703 & $(5,4)$ & 0.5296 & $(7,4)$ & 0.4990 & $(9,4)$ & 0.8719 & $(11,4)$ & 0.6432 \\
\hline$(1,6)$ & 0.9224 & $(3,6)$ & 0.6990 & $(5,6)$ & 0.8914 & $(7,5)$ & 0.4990 & $(9,5)$ & 0.9252 & $(11,5)$ & 0.6432 \\
\hline$(1,7)$ & 0.5009 & $(3,7)$ & 0.5009 & $(5,7)$ & 0.5009 & $(7,6)$ & 0.7701 & $(9,6)$ & 0.9626 & $(11,6)$ & 0.8345 \\
\hline$(1,8)$ & 0.3205 & $(3,8)$ & 0.1683 & $(5,8)$ & 0.2832 & $(7,8)$ & 0.3077 & $(9,7)$ & 0.5456 & $(11,7)$ & 0.6432 \\
\hline$(1,9)$ & 0.1654 & $(3,9)$ & 0.0827 & $(5,9)$ & 0.0747 & $(7,9)$ & 0.3077 & $(9,8)$ & 0.6600 & $(11,8)$ & 0.4519 \\
\hline$(1,10)$ & 0.4365 & $(3,10)$ & 0.3912 & $(5,10)$ & 0.3458 & $(7,10)$ & 0.6162 & $(9,10)$ & 0.6600 & $(11,9)$ & 0.4519 \\
\hline$(1,11)$ & 0.3567 & $(3,11)$ & 0.3567 & $(5,11)$ & 0.3567 & $(7,11)$ & 0.3567 & $(9,11)$ & 0.5480 & $(11,10)$ & 0.6432 \\
\hline$(1,12)$ & 0.5009 & $(3,12)$ & 0.2689 & $(5,12)$ & 0.3464 & $(7,12)$ & 0.4990 & $(9,12)$ & 0.6175 & $(11,12)$ & 0.6432 \\
\hline$(1,13)$ & 0.5916 & $(3,13)$ & 0.4636 & $(5,13)$ & 0.5009 & $(7,13)$ & 0.4681 & $(9,13)$ & 0.6549 & $(11,13)$ & 0.6432 \\
\hline$(1,14)$ & 0.5916 & $(3,14)$ & 0.3838 & $(5,14)$ & 0.4211 & $(7,14)$ & 0.5766 & $(9,14)$ & 0.6549 & $(11,14)$ & 0.6432 \\
\hline$(1,15)$ & 0.1201 & $(3,15)$ & 0.0747 & $(5,15)$ & 0.0747 & $(7,15)$ & 0.1654 & $(9,15)$ & 0.2660 & $(11,15)$ & 0.1523 \\
\hline$(1,16)$ & 0.2452 & $(3,16)$ & 0.2079 & $(5,16)$ & 0.1999 & $(7,16)$ & 0.1992 & $(9,16)$ & 0.4767 & $(11,16)$ & 0.4519 \\
\hline$(1,17)$ & 0.2660 & $(3,17)$ & 0.2660 & $(5,17)$ & 0.2660 & $(7,17)$ & 0.3567 & $(9,17)$ & 0.4573 & $(11,17)$ & 0.2287 \\
\hline$(1,18)$ & 0.0747 & $(3,18)$ & 0.0000 & $(5,18)$ & 0.0374 & $(7,18)$ & 0.3077 & $(9,18)$ & 0.0776 & $(11,18)$ & 0.4519 \\
\hline$(2,1)$ & 0.4602 & $(4,1)$ & 0.2367 & $(6,1)$ & 0.0776 & $(8,1)$ & 0.6794 & $(10,1)$ & 0.5634 & $(12,1)$ & 0.4990 \\
\hline$(2,3)$ & 0.6836 & $(4,2)$ & 0.3164 & $(6,2)$ & 0.2234 & $(8,2)$ & 0.6535 & $(10,2)$ & 0.4628 & $(12,2)$ & 0.4622 \\
\hline$(2,4)$ & 0.6836 & $(4,3)$ & 0.5852 & $(6,3)$ & 0.3010 & $(8,3)$ & 0.8317 & $(10,3)$ & 0.6088 & $(12,3)$ & 0.7311 \\
\hline$(2,5)$ & 0.5709 & $(4,5)$ & 0.4703 & $(6,4)$ & 0.3010 & $(8,4)$ & 0.8317 & $(10,4)$ & 0.5634 & $(12,4)$ & 0.6513 \\
\hline$(2,6)$ & 0.7765 & $(4,6)$ & 0.6990 & $(6,5)$ & 0.1085 & $(8,5)$ & 0.7168 & $(10,5)$ & 0.6541 & $(12,5)$ & 0.6535 \\
\hline$(2,7)$ & 0.6922 & $(4,7)$ & 0.5009 & $(6,7)$ & 0.2298 & $(8,7)$ & 0.8448 & $(10,6)$ & 0.9252 & $(12,6)$ & 0.8448 \\
\hline$(2,8)$ & 0.3464 & $(4,8)$ & 0.1683 & $(6,8)$ & 0.1551 & $(8,8)$ & 0.6922 & $(10,7)$ & 0.3838 & $(12,7)$ & 0.5009 \\
\hline$(2,9)$ & 0.2287 & $(4,9)$ & 0.1281 & $(6,9)$ & 0.0374 & $(8,9)$ & 0.4543 & $(10,8)$ & 0.4628 & $(12,8)$ & 0.4600 \\
\hline$(2,10)$ & 0.5371 & $(4,10)$ & 0.4365 & $(6,10)$ & 0.0747 & $(8,10)$ & 0.5371 & $(10,9)$ & 0.3399 & $(12,9)$ & 0.3824 \\
\hline$(2,11)$ & 0.5480 & $(4,11)$ & 0.3567 & $(6,11)$ & 0.1654 & $(8,11)$ & 0.5480 & $(10,11)$ & 0.3567 & $(12,10)$ & 0.5450 \\
\hline$(2,12)$ & 0.5377 & $(4,12)$ & 0.3487 & $(6,12)$ & 0.1551 & $(8,12)$ & 0.5400 & $(10,12)$ & 0.4549 & $(12,11)$ & 0.3567 \\
\hline$(2,13)$ & 0.6549 & $(4,13)$ & 0.5543 & $(6,13)$ & 0.1925 & $(8,13)$ & 0.6922 & $(10,13)$ & 0.3464 & $(12,13)$ & 0.5916 \\
\hline$(2,14)$ & 0.5751 & $(4,14)$ & 0.5543 & $(6,14)$ & 0.1925 & $(8,14)$ & 0.6922 & $(10,14)$ & 0.4549 & $(12,14)$ & 0.6203 \\
\hline$(2,15)$ & 0.2660 & $(4,15)$ & 0.1201 & $(6,15)$ & 0.0747 & $(8,15)$ & 0.2660 & $(10,15)$ & 0.0747 & $(12,15)$ & 0.1654 \\
\hline$(2,16)$ & 0.3085 & $(4,16)$ & 0.2079 & $(6,16)$ & 0.0374 & $(8,16)$ & 0.3458 & $(10,16)$ & 0.1683 & $(12,16)$ & 0.2452 \\
\hline$(2,17)$ & 0.4573 & $(4,17)$ & 0.2660 & $(6,17)$ & 0.0747 & $(8,17)$ & 0.4573 & $(10,17)$ & 0.2660 & $(12,17)$ & 0.3567 \\
\hline$(2,18)$ & 0.0000 & $(4,18)$ & 0.0000 & $(6,18)$ & 0.0000 & $(8,18)$ & 0.1172 & $(10,18)$ & 0.1861 & $(12,18)$ & 0.2739 \\
\hline
\end{tabular}


(b)

\begin{tabular}{|c|c|c|c|c|c|}
\hline Pair & $D_{i i^{\prime}}$ & Pair & $D_{i r^{\prime}}$ & Pair & $D_{i i^{\prime}}$ \\
\hline$(13,1)$ & 0.4083 & $(15,1)$ & 0.8799 & $(17,1)$ & 0.7339 \\
\hline$(13,2)$ & 0.3451 & $(15,2)$ & 0.7339 & $(17,2)$ & 0.5426 \\
\hline$(13,3)$ & 0.5364 & $(15,3)$ & 0.9252 & $(17,3)$ & 0.7339 \\
\hline$(13,4)$ & 0.4457 & $(15,4)$ & 0.8799 & $(17,4)$ & 0.7339 \\
\hline$(13,5)$ & 0.4990 & $(15,5)$ & 0.9252 & $(17,5)$ & 0.7339 \\
\hline$(13,6)$ & 0.8075 & $(15,6)$ & 0.9252 & $(17,6)$ & 0.9252 \\
\hline$(13,7)$ & 0.5319 & $(15,7)$ & 0.8345 & $(17,7)$ & 0.6432 \\
\hline$(13,8)$ & 0.3077 & $(15,8)$ & 0.7339 & $(17,8)$ & 0.5426 \\
\hline$(13,9)$ & 0.3451 & $(15,9)$ & 0.7339 & $(17,9)$ & 0.5426 \\
\hline$(13,10)$ & 0.6535 & $(15,10)$ & 0.9252 & $(17,10)$ & 0.7339 \\
\hline$(13,11)$ & 0.3567 & $(15,11)$ & 0.8477 & $(17,11)$ & 0.7713 \\
\hline$(13,12)$ & 0.4083 & $(15,12)$ & 0.8345 & $(17,12)$ & 0.6432 \\
\hline$(13,14)$ & 0.6139 & $(15,13)$ & 0.9252 & $(17,13)$ & 0.7339 \\
\hline$(13,15)$ & 0.0747 & $(15,14)$ & 0.9252 & $(17,14)$ & 0.7339 \\
\hline$(13,16)$ & 0.2366 & $(15,16)$ & 0.7339 & $(17,15)$ & 0.5375 \\
\hline$(13,17)$ & 0.2660 & $(15,17)$ & 0.4624 & $(17,16)$ & 0.5426 \\
\hline$(13,18)$ & 0.2170 & $(15,18)$ & 0.4519 & $(17,18)$ & 0.5426 \\
\hline$(14,1)$ & 0.4083 & $(16,1)$ & 0.7547 & $(18,1)$ & 0.9252 \\
\hline$(14,2)$ & 0.4249 & $(16,2)$ & 0.6915 & $(18,2)$ & 0.9999 \\
\hline$(14,3)$ & 0.6162 & $(16,3)$ & 0.7921 & $(18,3)$ & 0.9999 \\
\hline$(14,4)$ & 0.4457 & $(16,4)$ & 0.7921 & $(18,4)$ & 0.9999 \\
\hline$(14,5)$ & 0.5788 & $(16,5)$ & 0.8001 & $(18,5)$ & 0.9626 \\
\hline$(14,6)$ & 0.8075 & $(16,6)$ & 0.9626 & $(18,6)$ & 0.9999 \\
\hline$(14,7)$ & 0.4234 & $(16,7)$ & 0.8007 & $(18,7)$ & 0.6922 \\
\hline$(14,8)$ & 0.3077 & $(16,8)$ & 0.6541 & $(18,8)$ & 0.8828 \\
\hline$(14,9)$ & 0.3451 & $(16,9)$ & 0.5232 & $(18,9)$ & 0.9224 \\
\hline$(14,10)$ & 0.5450 & $(16,10)$ & 0.8317 & $(18,10)$ & 0.8139 \\
\hline$(14,11)$ & 0.3567 & $(16,11)$ & 0.5480 & $(18,11)$ & 0.5480 \\
\hline$(14,12)$ & 0.3796 & $(16,12)$ & 0.7547 & $(18,12)$ & 0.7260 \\
\hline$(14,13)$ & 0.3860 & $(16,13)$ & 0.7634 & $(18,13)$ & 0.7829 \\
\hline$(14,15)$ & 0.0747 & $(16,14)$ & 0.7921 & $(18,14)$ & 0.8914 \\
\hline$(14,16)$ & 0.2079 & $(16,15)$ & 0.2660 & $(18,15)$ & 0.5480 \\
\hline$(14,17)$ & 0.2660 & $(16,17)$ & 0.4573 & $(18,16)$ & 0.7054 \\
\hline$(14,18)$ & 0.1085 & $(16,18)$ & 0.2946 & $(18,17)$ & 0.4573 \\
\hline
\end{tabular}


Table 31. Appraisal score of facility layouts.

\begin{tabular}{ccc}
\hline Layouts & $S_{i}$ additive interval technique & Rank \\
\hline Layout 1 & 0.0243 & 14 \\
Layout 2 & 0.0531 & 5 \\
Layout 3 & 0.0185 & 16 \\
Layout 4 & 0.0245 & 17 \\
Layout 5 & 0.0135 & 18 \\
Layout 6 & 0.0069 & 10 \\
Layout 7 & 0.0345 & 7 \\
Layout 8 & 0.0483 & 8 \\
Layout 9 & 0.0453 & 12 \\
Layout 10 & 0.0255 & 6 \\
Layout 11 & 0.0495 & 9 \\
Layout 12 & 0.0415 & 11 \\
Layout 13 & 0.0262 & 15 \\
Layout 14 & 0.0226 & 2 \\
Layout 15 & 0.1939 & 4 \\
Layout 16 & 0.0867 & 3 \\
Layout 17 & 0.1099 & 1 \\
Layout 18 & 0.1985 & \\
\hline
\end{tabular}

Table 32. Comparison and ranking of facility layout designs using various methods.

\begin{tabular}{|c|c|c|c|c|c|c|c|c|c|}
\hline & $\begin{array}{l}\text { Score using } \\
\text { EVAMIX } \\
\text { method }\end{array}$ & Rank & $\begin{array}{c}\text { Score using } \\
\text { AHP/DEA } \\
\text { method }\end{array}$ & Rank & $\begin{array}{l}\text { Score using } \\
\text { TOPSIS } \\
\text { meta model }\end{array}$ & Rank & $\begin{array}{c}\text { Rank using } \\
\text { GRA } \\
\text { method }\end{array}$ & $\begin{array}{l}\text { Rank using } \\
\text { TOPSIS } \\
\text { method }\end{array}$ & $\begin{array}{c}\text { Rank using } \\
\text { SAW } \\
\text { method }\end{array}$ \\
\hline Layout 1 & 0.0243 & 14 & 91.69 & 7 & 57.857 & 18 & 10 & 17 & 14 \\
\hline Layout 2 & 0.0531 & 5 & 98.45 & 2 & 59.858 & 14 & 8 & 8 & 8 \\
\hline Layout 3 & 0.0185 & 16 & 86.39 & 12 & 58.653 & 17 & 15 & 15 & 15 \\
\hline Layout 4 & 0.0245 & 13 & 89.94 & 8 & 58.666 & 16 & 11 & 16 & 12 \\
\hline Layout 5 & 0.0135 & 17 & 86.44 & 11 & 59.871 & 13 & 13 & 14 & 11 \\
\hline Layout 6 & 0.0069 & 18 & 96.62 & 3 & 59.789 & 15 & 16 & 9 & 18 \\
\hline Layout 7 & 0.0345 & 10 & 80.77 & 15 & 64.760 & 8 & 17 & 13 & 16 \\
\hline Layout 8 & 0.0483 & 7 & 96.51 & 4 & 60.518 & 12 & 7 & 12 & 9 \\
\hline Layout 9 & 0.0453 & 8 & 95.69 & 5 & 65.223 & 7 & 5 & 6 & 5 \\
\hline Layout 10 & 0.0255 & 12 & 87.44 & 9 & 67.824 & 5 & 9 & 5 & 7 \\
\hline Layout 11 & 0.0495 & 6 & 100 & 1 & 76.219 & 3 & 3 & 1 & 3 \\
\hline Layout 12 & 0.0415 & 9 & 85.72 & 14 & 60.722 & 11 & 18 & 18 & 17 \\
\hline Layout 13 & 0.0262 & 11 & 86.29 & 13 & 63.536 & 9 & 14 & 10 & 13 \\
\hline Layout 14 & 0.0226 & 15 & 86.66 & 10 & 62.039 & 10 & 12 & 11 & 10 \\
\hline Layout 15 & 0.1939 & 2 & 100 & 1 & 80.379 & 2 & 1 & 2 & 1 \\
\hline Layout 16 & 0.0867 & 4 & 96.74 & 2 & 68.175 & 4 & 6 & 4 & 6 \\
\hline Layout 17 & 0.1099 & 3 & 94.63 & 6 & 80.428 & 1 & 2 & 3 & 2 \\
\hline Layout 18 & 0.1985 & 1 & 100 & 1 & 65.524 & 6 & 4 & 7 & 4 \\
\hline
\end{tabular}


frontier proposed by [62] shows 11,15 and 18 as leading candidate of facility layout designs. Than the modified DEA frontier could suggest the best among these three.

The proposed methodology gave final solution by considering a large number of design alternatives by avoiding any problem of same score values. Design alternative 18 is the present alternative and which come out with maximum score in the present approach. The top ranking of the design layouts using integrated EVAMIX method are matching with the results obtained by previous researchers and given in Table 32. The alternative 18 is the existing facility layout and fulfils all the requirements of manufacturing environment of application. It is clear from the Table 32, that alternative 18, 17, 15 and 11 are found to be more efficient compared any other layout design.

\section{Conclusions}

The integrated EVAMIX methodology is suggested for decision making in the industrial environment to solve the decision making problems from a large number of available alternatives for a given problem. Five examples are included to illustrate the method. The proposed method incorporates the cardinal and ordinal attributes in a separate pattern combined together to provide a better evaluation of the alternatives. The use of AHP in the decision making allows the decision maker to assign the values of relative importance to the attribute based on his/her preferences. The Appraisal scores calculated by the method evaluate and rank the alternatives and lead to selection of a suitable alternative.

The integrated EVAMIX method is a general outranking method and can deal with any number of cardinal and ordinal attributes simultaneously. The method is logical and provides good elaboration of the ranking method. The suggested methodology can be used for any type of selection problem having any number of attributes.

\section{REFERENCES}

[1] R. V. Rao, "Decision Making in Manufacturing Environment Using Graph Theory and Fuzzy Multiple Attribute Decision Making Methods," Springer Series in Advanced Manufacturing, London, Vol. 2, 2013, pp. 1-5.

[2] P. Chatterjee, V. M. Athawale and S. Chakraborty, "Material Selection Using Complex Proportional Assessment and Evaluation of Mixed Data Methods," Material and Design, Vol. 32, No. 2, 2011, pp. 851-860.

[3] H. Voogd, "Multicriteria Evaluation with Mixed Qualitative and Quantitative Data," Environment and Planning Bulletin, Vol. 9, No. 2, 1982, pp. 221-236.

[4] H. Voogd, "Multicriteria Evaluation for Urban and Regional Planning," Pion, London, 1983.

[5] J. M. Martel and B. Matarazzo, "Other Outranking Ap- proaches," In: F. J. Salvatore and G. M. Ehrgott, Eds., Multiple Criteria Decision Analysis: State of the Art Surveys, Springer, New York, 2005, pp. 197-262.

[6] P. Nijkamp, P. Rietveld and H. Voogd, "Multicriteria Evaluation in Physical Planning," North Holland, Amsterdam, 1990, pp. 65-100.

[7] S. Hajkowicz and A. Higgins, "A Comparison of Multiple Criteria Analysis Techniques for Water Resource Management," European Journal of Operation Research, Vol. 184 , No. 1,2008 , pp. 255-265. http://dx.doi.org/10.1016/j.ejor.2006.10.045

[8] E. S. Chung and K. S. Lee, "Identification of Spatial Ranking of Hydrological Vulnerability Using Multi-Criteria Decision Making Techniques: Case Study of Korea," Water Resource Management, Vol. 23, No. 12, 2009, pp. 2395-2416. http://dx.doi.org/10.1007/s11269-008-9387-9

[9] L. Ustinovichius, E. K. Zavadskas and V. Podvezko, "Application of a Quantitative Multiple Criteria Decision Making (MCDM-1) Approach to the Analysis of Investments in Construction," Control and Cybernetics, Vol. 36, No. 1, 2007, pp. 251-268.

[10] I. Jeffreys, "The Use of Compensatory and Non-Compensatory Multi-Criteria Analysis for Small-Scale Forestry," Small-Scale Forest Ecol Manage Policy, Vol. 3, No. 1, 2004, pp. 99-117.

[11] S. J. Chen and C. L. Hwang, "Fuzzy Multiple Attribute Decision Making-Methods and Applications," Lecture Notes in Economics and Mathematical Systems, Springer, New York, 1992.

[12] T. L. Saaty, "The Analytic Hierarchy Process," McGrawHill, New York, 1980.

[13] T. L. Saaty and L. G. Vrgas, "The Logic of Priorities, Applications in Business, Energy, Health, Transportation," Kluwer-Nijhoff, The Hague, 1981.

[14] T. L. Saaty, "Absolute and Relative Measurement with the AHP. The Most Livable Cities in the United States," Socio-Economic Planning Sciences, Vol. 20, No. 6, 1986, pp. 327-331. http://dx.doi.org/10.1016/0038-0121(86)90043-1

[15] T. L. Saaty, "Fundamentals of Decision Making and Priority Theory with AHP," RWS Publications, Pittsburg, 2000.

[16] S. Xu, "References on the Analytic Hierarchy Process," Institute of Systems Engineering, Tianjin University, Tianjin, 1986.

[17] G. T. Fechner, "Elements of Psychophysics," Holt, Rinehart and Winston, New York, 1860.

[18] L. L. Turstone, "A Law of Comparative Judgements," Psychological Reviews, Vol. 34, No. 4, 1927, pp. 272286.

[19] K. L. Edwards, "Selecting Materials for Optimum Use in Engineering Components," Mater \& Design, Vol. 26, No. 5, 2005, pp. 469-473. http://dx.doi.org/10.1016/i.matdes.2004.07.004

[20] M. S. Chen, "A New Method for Tool Steel Materials under Fuzzy Environment," Fuzzy Sets and System, Vol. 92, No. 3, 1997, pp. 265-274. 
http://dx.doi.org/10.1016/S0165-0114(96)00189-3

[21] H. D. Jee and K. J. Kang, "A Method for Optimal Material Selection Aided with Decision Making Theory," Materials \& Design, Vol. 21, No. 3, 2000, pp. 199-206. http://dx.doi.org/10.1016/S0261-3069(99)00066-7

[22] K. M. Rajan and K. Narasimhan, "An Approach to Selection of Material and Manufacturing Processes for Rocket Motor Cases Using Weighted Performance Index," Journal of Materials Engineering and Performance, Vol. 11, No. 4, 2002, pp. 444-449. http://dx.doi.org/10.1361/105994902770343980

[23] N. S. Ermolaeva, M. B. G. Castro and P. V. Kandachar, "Materials Selection for an Automotive Structure by Integrating Structural Optimization with Environmental Impact Assessment," Materials \& Design, Vol. 25, No. 8, 2004, pp. 689-698. http://dx.doi.org/10.1016/j.matdes.2004.02.021

[24] R. V. Rao and J. P. Davim, "A Decision-Making Framework Model for Material Selection Using a Combined Multiple Attribute Decision-Making Method," The International Journal of Advanced Manufacturing Technology, Vol. 35, No. 7-8, 2008, pp. 751-760.

http://dx.doi.org/10.1007/s00170-006-0752-7

[25] P. Chatterjee, V. M. Athawale and S. Chakraborty, "Selection of Materials Using Compromise Ranking and Outranking Methods," Materials \& Design, Vol. 30, No. 10, 2009, pp. 4043-4053.

http://dx.doi.org/10.1016/j.matdes.2009.05.016

[26] A. Shanian and O. Savadogo, "A Material Selection Model Based on the Concept of Multiple Attribute Decision Making," Materials \& Design, Vol. 27, No. 4, 2006, pp. 329-337. http://dx.doi.org/10.1016/j.matdes.2004.10.027

[27] B. D. Manshadi, H. Mahmudi, A. Abedian and R. Mahmudi, "A Novel Method for Materials Selection in Mechanical Design: Combination of Non-Linear Linearization and a Modified Digital Logic Method," Materials \& Design, Vol. 28, No. 1, 2007, pp. 8-15. http://dx.doi.org/10.1016/j.matdes.2005.06.023

[28] I. Ribeiro, P. Peças, A. Silva and E. Henriques, "Life Cycle Engineering Methodology Applied to Material Selection, a Fender Case Study," Journal of Cleaner Production, Vol. 16, No. 17, 2008, pp. 1887-1899. http://dx.doi.org/10.1016/j.jclepro.2008.01.002

[29] P. Pecas, I. Ribeiro, A. Silva and E. Henriques, "Comprehensive Approach for Informed Life Cycle-Based Material Selection," Mater Design, Vol. 43, 2013, pp. 220232. http://dx.doi.org/10.1016/j.matdes.2012.06.064

[30] C. D. Rudd, A. C. Long, K. N. Kendall and C. G. E. Mangin, "Liquid Molding Technologies," Woodhead Publishing Ltd., Cambridge, 1997. http://dx.doi.org/10.1533/9781845695446

[31] K. Potter, "Materials for RTM. Resin Transfer. Resin Transfer Molding," Chapman and Hall, London, 1997, p. 200.

[32] D. S. Jung and G. L. Dai, "Manufacture of Composite Screw Rotors for Air Compressors by RTM Process," Journal of Materials Processing Technology, Vol. 113, No. 1-3, 2001, pp. 196-201.
http://dx.doi.org/10.1016/S0924-0136(01)00655-0

[33] W. D. Brouwer, E. C. F. C. Van Herpt and M. Labordus, "Vacuum Injection Molding for Large Structural Applications," Composites Part-A: Applied Science and Manufacturing, Vol. 34, No. 6, 2003, pp. 551-558. http://dx.doi.org/10.1016/S1359-835X(03)00060-5

[34] K. Han, S. Jiang, C. Zhang and B. Wang, "Flow Modelling and Simulation of SCRIMP for Composites Manufacturing," Composites Part-A: Applied Science and Manufacturing, Vol. 31, No. 1, 2004, pp. 79-86. http://dx.doi.org/10.1016/S1359-835X(99)00053-6

[35] R. T. Durai Prabhakaran, B. J. C. Babu and V. P. Agrawal, "Structural Modeling and Analysis of Composite Product System: A Graph Theoretic Approach," Journal of Composite Materials, Vol. 40, No. 22, 2006, pp. 19872007. http://dx.doi.org/10.1177/0021998306061318

[36] K. L. Reifsnider, "Modeling of the Interphase in Polymer-Matrix Composite Material Systems," Composites, Vol. 25, No. 7, 1994, pp. 461-469.

http://dx.doi.org/10.1016/0010-4361(94)90170-8

[37] H. Liu, A. Uhlherr and M. K. Bannister, "Quantitative Structure-Property Relationships for Composites: Prediction of Glass Transition Temperatures for Epoxy Resins," Polymer, Vol. 45, No. 6, 2004, pp. 2051-2060. http://dx.doi.org/10.1016/j.polymer.2004.01.008

[38] J. C. Lin, M. H. Nien and F. M. Yu, "Morphological Structure, Processing and Properties of Propylene Polymer Matrix Nanocomposites," Composite Structures, Vol. 71, No. 1, 2005, pp. 78-82. http://dx.doi.org/10.1016/j.compstruct.2004.09.021

[39] R. T. Durai Prabhakaran, B. J. C. Babu and V. P. Agrawal, "Optimum Selection of a Composite Product System Using AMDM Approach," Material and Manufacturing Processes, Vol. 21, No. 8, 2006, pp. 883-891. http://dx.doi.org/10.1080/10426910600773472

[40] W. Ting and C. X. Bing, "Thermal Power Plant Sitting Based on TOPSIS Method," Procedia Engineering, Vol. 15, 2011, pp. 5384-5388. http://dx.doi.org/10.1016/j.proeng.2011.08.998

[41] J. H. Yan, "Comprehensive Evaluation Theory and Methods," Science Press, Beijing, 2002.

[42] Y. L. Jing, X. N. Dong and Y. Z. Shi, "The Sitting of Thermal Power Plant by the Method of Triangular Fuzzy Numbers," Quantitative \& Technical Economics, 2003.

[43] Q. L. Dong, "The Application of Entropy-Based Fuzzy Comprehensive Evaluation Method in the Sitting of Thermal Power Plant," Experimental Investigation, 2010.

[44] X. N. Dong, "Gray-Level Analysis Used in the Optimal Decision-Making of Thermal Power Plant Site," Journal of Power System Technology, Vol. 11, 1994.

[45] M. Y. Hai, “Application Manual of Economic Evaluation and Technological Transformation of Electric Power Industry," Jilin Photography Press, Jilin, 2005.

[46] P. Lu, M. Xing and Y. Kang, "AHP Method Used in the Optimal Planning of Power Plant Site Selection," Journal of North China Electric Power University, Vol. 2, No. 4, 1994.

[47] P. Danijela, V. Ivana, V. Katarina and T. Dusan, "Appli- 
cation of DEA to the Analysis of AGV Fleet Operations in a Port Container Terminal," Procedia Social and Behavioural Sciences, Vol. 20, 2011, pp. 816-825.

[48] P. Ioannou, H. Jula, C. I. Liu, K. Vukadinovic, H. Pourmohammadi and E. Dougherty Jr., "Advanced Material Handling: Automated Guided Vehicles in Agile Ports," CCDoTT Technical Report, Centre for Advanced Transportation Technologies, University of Southern California, Los Angeles, 2001.

[49] M. G. Maria and T. Lourdes, "Reforms and Infrastructure Efficiency in Spain's Container Ports," Transportation Research Part A: Policy and Practice, Vol. 42, No. 1, 2008, pp. 243-257.

[50] C. P. Barros, "Measurement of Efficiency of Portuguese Seaport Authorities with DEA," International Journal of Transport Economics, Vol. 30, No. 3, 2003, pp. 335-354.

[51] K. Cullinane, D. W. Song, P. Ji and T. F. Wang, "An Application of DEA Windows Analysis to Container Port Production Efficiency," Review of Network Economics, Vol. 3, No. 2, 2004, pp. 1-23.

[52] K. Cullinane and T. F. Wang, "The Efficiency of European Container Ports: Across-Sectional Data Envelopment Analysis," International Journal of Logistics: Research and Applications, Vol. 9, No. 1, 2006, pp. 19-31. http://dx.doi.org/10.1080/13675560500322417

[53] I. E. Kaisar, S. Pathomsiri and A. Haghani, "Efficiency Measurement of US Ports Using Data Envelopment Analysis," National Urban Freight Conference, Long Beach California, 1-3 February 2006, p. 16.

[54] C. I. Liu, H. Jula, K. Vukadinovic and P. Ioannou, "Automated Guided Vehicle System for Two Container Yard Layouts," Transportation Research Part C: Emerging Technologies, Vol. 12, No. 5, 2004, pp. 349-368. http://dx.doi.org/10.1016/j.trc.2004.07.014

[55] H. Min and B. I. Park, "Evaluating the Inter-Temporal Efficiency Trends of International Container Terminals Using Data Envelopment Analysis," International Journal of Integrated Supply Management, Vol. 1, No. 3, 2005, pp. 258-277.

http://dx.doi.org/10.1504/IJISM.2005.005950

[56] D. Pjevčević and K. Vukadinović, "Efficiency Measurement of Bulk Cargo Handling at River Port Using Data
Envelopment Analysis," Tehnika, Vol. 65, No. 4, 2010, pp. 14-19.

[57] T. Yang and C. Kuo, "A Hierarchical AHP/DEA Methodology for the Facilities Layout Design Problem," European Journal of Operational Research, Vol. 147, No. 1, 2003, pp. 128-136.

http://dx.doi.org/10.1016/S0377-2217(02)00251-5

[58] L. C. Lin and G. P. Sharp, "Quantitative and Qualitative Indices for the Plant Layout Evaluation Problem," European Journal of Operational Research, Vol. 116, No. 1, 1999, pp. 100-117.

http://dx.doi.org/10.1016/S0377-2217(98)00046-0

[59] L. C. Lin and G. P. Sharp, "Application of the Integrated Framework for the Plant Layout Evaluation Problem," European Journal of Operational Research, Vol. 116, No. 1, 1999, pp. 118-138. http://dx.doi.org/10.1016/S0377-2217(98)00174-X

[60] J. A. Tomkins, J. A. White, Y. Bozer and J. M. Tanchoco, "Facilities Planning," John Wiley \& Sons, New York, 2003.

[61] R. Muther, "Systematic Layout Planning," 2nd Edition, Cahners Books, Boston, 1973.

[62] Y. Taho and K. Chunwei, "A Hierarchical AHP/DEA Methodology for the Facilities Layout Design Problem," European Journal of Operational Research, Vol. 147, No. 1, 2003, pp. 128-136.

[63] T. Yang and C. C Hung, "2007. Multi-Attribute Decision Making Methods for Plant Layout Design Problem," Robotics and Computer Integrated Manufacturing, Vol. 23, No. 1, 2007, pp. 126-137. http://dx.doi.org/10.1016/j.rcim.2005.12.002

[64] Y. Y. Kuo, T. H. Yang and G. W. Huang, "The Use of Grey Relational Analysis in Solving Multiple Attribute Decision-Making Problems," Computer \& Industrial Engineering, Vol. 55, No. 1, 2008, pp. 80-93. http://dx.doi.org/10.1016/j.cie.2007.12.002

[65] Y. T. İç, "An Experimental Design Approach Using TOPSIS Method for the Selection of Computer-Integrated Manufacturing Technologies," Robotics and ComputerIntegrated Manufacturing, Vol. 28, No. 2, 2012, pp. 245 256. http://dx.doi.org/10.1016/j.rcim.2011.09.005 